\title{
Range-based Covariance Estimation using High-Frequency Data: The Realized Co-Range*
}

\author{
Karim Bannouh ${ }^{\dagger}$ \\ Econometric Institute \\ Erasmus University Rotterdam
}

\author{
Dick van Dijk $\ddagger$ \\ Econometric Institute \\ Erasmus University Rotterdam \\ Decomometric Institute
}

Martin Martens ${ }^{\S}$

Department of Finance

Erasmus University Rotterdam

Econometric Institute Report EI 2007-53

January 15, 2008

\begin{abstract}
We introduce the realized co-range, utilizing intraday high-low price ranges to estimate asset return covariances. Using simulations we find that for plausible levels of bid-ask bounce and infrequent and non-synchronous trading the realized co-range improves upon the realized covariance, which uses cross-products of intraday returns. One advantage of the co-range is that in an ideal world it is five times more efficient than the realized covariance when sampling at the same frequency. The second advantage is that the upward bias due to bid-ask bounce and the downward bias due to infrequent and non-synchronous trading partially offset each other. In a volatility timing strategy for S\&P500, bond and gold futures we find that the co-range estimates are less noisy as exemplified by lower transaction costs and also higher Sharpe ratios when using more weight on recent data for predicting covariances.
\end{abstract}

Keywords: Realized covariance; realized co-range; high-frequency data; market microstructure noise; bias-correction

JEL Classification: C13, C14, G11

\footnotetext{
*We thank participants of the conference on "Multivariate Volatility Models", Faro, October 2007, for helpful comments and suggestions.

${ }^{\dagger}$ Econometric Institute, Erasmus University Rotterdam, P.O. Box 1738, NL-3000 DR Rotterdam, Netherlands, e-mail: bannouh@few.eur.nl

${ }^{\ddagger}$ Econometric Institute, Erasmus University Rotterdam, P.O. Box 1738, NL-3000 DR Rotterdam, The Netherlands, e-mail: djvandijk@few.eur.nl (corresponding author)

$\S$ Department of Finance, Erasmus University Rotterdam, P.O. Box 1738, NL-3000 DR Rotterdam, The Netherlands, e-mail: mmartens@few.eur.nl
} 


\section{Introduction}

This paper develops a novel estimator of the daily quadratic covariation between asset returns, based on high-frequency intraday price ranges. This so-called realized co-range estimator combines two recent ideas that have revived the use of highlow ranges for estimating the volatility and covariance of asset returns. First, it employs the realized range, independently introduced by Martens and Van Dijk (2007) and Christensen and Podolskij (2007), to estimate daily volatility by means of the sum of squared intraday price ranges. Second, it adopts the suggestion of Brandt and Diebold (2006) to use range-based volatility estimates of a portfolio and the individual assets to estimate their covariance.

The increasing availability of high-frequency asset price data has led to a rapidly expanding literature on the use of intraday prices to measure, model and forecast daily volatility, see Andersen et al. (2006) and McAleer and Medeiros (in press) for recent reviews. Based on the theoretical results of Barndorff-Nielsen and Shephard (2002) and Andersen et al. (2001, 2003), in the absence of microstructure noise the sum of squared intraday returns, called realized variance, is an unbiased and highly efficient estimator of the daily quadratic variation. The benefits of high-frequency data continue to hold in a multivariate context as intraday returns provide more accurate estimates of the daily covariance between asset returns. Barndorff-Nielsen and Shephard (2004) show that the realized covariance, that is, the sum of crossproducts of intraday returns, converges in probability to the quadratic covariation. The economic value of using realized covariances in a volatility timing strategy has been explored by Fleming et al. (2003) and De Pooter et al. (in press), who find that a risk-averse investor is willing to pay between 50 and 200 basis points per annum to switch from covariance measurement based on daily data to intraday data.

Intraday price ranges have only recently been considered for the purpose of estimating daily volatility. This might appear surprising, given that it has been known since Parkinson (1980) that the high-low range is considerably more efficient as an estimator of volatility than the squared return, with a variance that is five times smaller. Martens and Van Dijk (2007) and Christensen and Podolskij (2007) exploit this result for developing an estimator of daily volatility based on intraday ranges, which is more efficient than the realized variance by the same 5:1 ratio. One 
possible reason for ignoring the range in the context of high-frequency data is that the extension to the multivariate case, that is, to estimate the covariation between asset returns, was an unresolved challenge until the recent proposal by Brandt and Diebold (2006). This exploits the fact that, under no-arbitrage conditions, the covariance between two assets can be expressed in terms of their individual variances and the variance of a portfolio of the two assets. The range-based covariance estimator is then obtained by using daily price ranges to estimate these variances. The main contribution of this paper is to combine these two ideas to provide an intraday range-based covariance estimator. In particular, we employ the realized range of Martens and Van Dijk (2007) and Christensen and Podolskij (2007) for estimating the daily volatilities that enter the co-range estimator of Brandt and Diebold (2006), which results in the novel realized co-range estimator. Given the relative efficiency of the realized range estimator, we expect the realized co-range also to be more efficient than the realized covariance.

Market microstructure effects pose a serious challenge to the use of high-frequency data. In the univariate case, the most important effect is due to bid-ask bounce, which renders the standard realized variance estimator biased and inconsistent. This has led to several proposals for bias-corrected realized volatility estimators on the one hand, and for determining the optimal sampling frequency for the standard realized variance estimator on the other hand. ${ }^{1}$ As discussed in Martens and Van Dijk (2007) and Christensen and Podolskij (2007), the realized range estimator in addition suffers from infrequent trading. This causes a downward bias as the observed minimum and maximum price over- and underestimate the true minimum and maximum, respectively. In the multivariate case, the greatest concern for realized covariance estimators is the presence of non-synchronous trading. As a result of assets trading at different times, estimates of their covariance will be biased towards zero. This so-called Epps (1979) effect becomes worse with increasing sampling frequency. The impact of microstructure noise on the realized covariance estimator has recently received a considerable amount of attention. For recent contributions we

\footnotetext{
${ }^{1}$ The choice of sampling frequency reflects the trade-off between accuracy, which is theoretically optimized using the highest possible frequency, and microstructure noise, which calls for lowering the data frequency. See Oomen (2005), Zhang et al. (2005), Aït-Sahalia et al. (2005), Bandi and Russell (in press, 2006), Hansen and Lunde (2006) and Awartani et al. (2007) among others, for recent discussions.
} 
refer to Bandi and Russell (in press), Sheppard (2005), Hayashi and Yoshida (2005), Bandi et al. (in press), Griffin and Oomen (2006), Zhang (2006) and Voev and Lunde (2007).

In this paper we propose the use of an additive bias-correction for the realized co-range, where we add the average difference between the covariance estimates based on daily ranges and on intraday ranges over the previous $Q$ trading days to the standard realized co-range estimate. The main advantage of this additive biascorrection is that it deals with the "net" bias that arises due to different possible microstructure effects. This contrasts to other bias-corrections that have been put forward in the context of range-based volatility estimators, which correct only for a single source of bias such as infrequent trading, see Rogers and Satchell (1991) and Christensen and Podolskij (2007) for examples.

We assess the performance of the realized co-range estimator by means of extensive simulation experiments and an empirical application. In the simulations we start from an idealized continuous-time setting without microstructure noise, where we find that the realized co-range outperforms the returns-based realized covariance estimator, as expected. In more realistic settings that incorporate bid-ask bounce, infrequent trading and non-synchronous trading, we find that the impact of the different microstructure effects is reduced successfully by using the additive bias-correction. The bias-corrected realized co-range is more efficient than the corrected realized covariance estimator for plausible levels of noise, as is the case for the uncorrected daily co-range compared to the daily covariance estimator.

In the empirical application we focus on the economic value of high-frequency intraday ranges for estimating covariances. We adopt the framework developed by Fleming et al. (2003) and use the realized co-range in a dynamic volatility timing strategy for constructing mean-variance efficient portfolios consisting of futures on stocks, bonds and gold. Sampling at the popular 5-minute frequency, we find that the bias-corrected realized co-range and realized covariance estimators provide similar results in terms of portfolio return and risk, before transaction costs. At first sight, this indicates that both estimators render similar (co)variance dynamics. Closer inspection reveals that the correlation estimates obtained from the realized co-range are less 'noisy' than those resulting from the realized covariance. In the volatility timing strategy this causes less variation in the realized co-range portfolio 
weights, which implies lower turnover and, hence, lower transaction costs. Taking transaction costs into account, we find that a mean-variance investor would be willing to pay 60 basis points per annum to switch from the realized covariance to the realized co-range when the decay parameter of the used exponential weighting scheme is estimated using a maximum-likelihood procedure. A sensitivity analysis of the decay parameter, which determines how much weight is put on recent estimates for predicting covariances, illustrates that the realized co-range outperforms the realized covariance also in terms of risk-return characteristics and therefore Sharpe ratios when more weight is put on the most recent estimate.

The remainder of this paper is organized as follows. In Section 2 we discuss the realized (co-)variance and realized (co-)range estimators. In Section 3 we use Monte Carlo simulations to analyze the properties of the realized co-range and realized covariance estimators in the presence of noise. In Section 4 we consider the empirical application to volatility timing strategies. We conclude in Section 5.

\section{Volatility and covariation estimators}

The traditional way to estimate daily volatility ex post is by means of the daily squared return. Although this estimator is unbiased, it also is very noisy and has a high variance. In order to improve accuracy, high-frequency intra-day returns may be used. Dividing day $t$ into $M$ non-overlapping intervals of length $\Delta=1 / M$, the realized variance estimator is given by

$$
R V_{t}^{\Delta} \equiv \sum_{m=1}^{M}\left(\log P_{t, m}-\log P_{t, m-1}\right)^{2}
$$

where $P_{t, m}$ is the last observed transaction price during the $m$-th interval on day $t$. In the absence of noise and under weak regularity conditions for the stochastic log-price process, the realized variance is an unbiased and consistent estimator of the daily integrated variance, see Barndorff-Nielsen and Shephard (2002) and Andersen et al. (2003), among others.

Further efficiency gains can be achieved by exploiting the superior properties of the range as a volatility proxy compared to squared returns. In particular, Martens and Van Dijk (2007) and Christensen and Podolskij (2007) define the realized range 
as the sum of intraday price ranges, that is,

$$
R R_{t}^{\Delta}=\sum_{m=1}^{M} \frac{1}{4 \log 2}\left(\log H_{t, m}-\log L_{t, m}\right)^{2},
$$

where the high price $H_{t, m}$ and the low price $L_{t, m}$ are defined as the maximum and minimum, respectively, of all transaction prices observed during the $m$-th interval on day $t$. Assuming that the asset price $P_{t}$ follows a geometric Brownian motion with constant instantaneous variance $\sigma^{2}$, the variance of the realized range estimator is equal to $0.407 \sigma^{4} \Delta^{2}$, compared to $2 \sigma^{4} \Delta^{2}$ for the realized variance. Hence, the variance of the realized range is approximately five times smaller than the variance of the realized variance estimator. Christensen and Podolskij (2007) show that the realized range remains consistent and relatively efficient in case volatility is timevarying, requiring only mild assumptions on the stochastic volatility process $\sigma_{t}$.

\subsection{Realized covariance and realized co-range}

The intraday return-based realized variance in (1) provides an efficient estimator for the variances of individual asset returns. Similarly, the realized covariance between assets $i$ and $j$ can be obtained by summing cross-products of intraday returns,

$$
R V C O V_{t}^{\Delta}=\sum_{m=1}^{M} r_{t, i, m} r_{t, j, m}
$$

where $r_{t, i, m}$ is the continuously compounded return on asset $i$ during the $m$-th interval on day $t$. Barndorff-Nielsen and Shephard (2004) study the properties of the realized covariance, showing that it is consistent for the daily integrated covariation under mild regularity conditions.

Brandt and Diebold (2006) introduce a simple but effective way to estimate the covariance by combining range-based estimates of the variances of two individual assets and of a portfolio composed of these assets. Consider a portfolio of assets $i$ and $j$ with weights $\lambda_{i}$ and $\lambda_{j}=1-\lambda_{i}$, with asset returns denoted as $r_{i}$ and $r_{j}$. The variance of the portfolio return $r_{p} \equiv \lambda_{i} r_{i}+\lambda_{j} r_{j}$ is given by

$$
\operatorname{Var}\left[r_{p}\right]=\lambda_{i}^{2} \operatorname{Var}\left[r_{i}\right]+\lambda_{j}^{2} \operatorname{Var}\left[r_{j}\right]+2 \lambda_{i} \lambda_{j} \operatorname{Cov}\left[r_{i}, r_{j}\right]
$$

such that, after rearranging

$$
\operatorname{Cov}\left[r_{i}, r_{j}\right]=\frac{1}{2 \lambda_{i} \lambda_{j}}\left(\operatorname{Var}\left[r_{p}\right]-\lambda_{i}^{2} \operatorname{Var}\left[r_{i}\right]-\lambda_{j}^{2} \operatorname{Var}\left[r_{j}\right]\right) .
$$


The daily co-range estimator of Brandt and Diebold (2006) is obtained by using the daily high-low range of the corresponding prices of the portfolio and the individual assets as estimators of three variances on the right-hand side of (4). Brandt and Diebold (2006) find that, in the absence of noise, the efficiency of the daily co-range is between that of the realized covariance in (3) computed using 3-hour and 6-hour intraday returns. Furthermore, the daily co-range turns out to be robust to the effects of microstructure noise such as bid-ask bounce and asynchronous trading, which severely affect the realized covariance.

We combine the idea of using intraday ranges for estimating daily volatilities, with the idea of estimating the daily covariance from estimates of the volatilities of the individual assets and of the portfolio. Specifically, using the realized range defined in (2) for estimating the three variances on the right-hand side of (4), we obtain the realized co-range estimator

$$
R R C O V_{t}^{\Delta}=\frac{1}{2 \lambda_{i} \lambda_{j}}\left(R R_{p, t}^{\Delta}-\lambda_{i}^{2} R R_{i, t}^{\Delta}-\lambda_{j}^{2} R R_{j, t}^{\Delta}\right)
$$

where $R R_{p, t}$ is the realized range of the portfolio, and $R R_{i, t}$ and $R R_{j, t}$ are the realized ranges of the individual assets. Each realized range is estimated using (2). ${ }^{2}$ It is important to note that the high (low) price of asset $i$ in a given intraday interval will probably be obtained at a different point in time than the high (low) price of asset $j$. The high-low range of the portfolio then is not the same as the weighted sum of the individual ranges. Therefore, it is necessary to construct a portfolio price path at the highest possible sampling frequency and estimate the realized range of the portfolio, $R R_{p, t}$, using (2).

\subsection{Bias-correction}

As discussed in the introduction, market microstructure effects hamper the use of high-frequency data for estimating daily variances and covariances. First, both the

\footnotetext{
${ }^{2}$ Note that (4) can also be used to estimate the daily covariance with realized variances, by using $R V$ as defined in (1) to estimate the variances on the right-hand side. In the absence of
} noise, this yields exactly the realized covariance as given in (3), as

$$
\frac{1}{2 \lambda_{i} \lambda_{j}}\left(\sum_{m=1}^{M}\left(\lambda_{i} r_{i, m}+\lambda_{j} r_{j, m}\right)^{2}-\lambda_{i}^{2} \sum_{m=1}^{M} r_{i, m}^{2}-\lambda_{j}^{2} \sum_{m=1}^{M} r_{j, m}^{2}\right)=\sum_{m=1}^{M} r_{i, m} r_{j, m} .
$$


realized variance in (1) and the realized range in (2) suffer from an upward bias due to the presence of bid-ask bounce. For example, when trading is continuous, the observed high price in a given interval is an ask and the observed low price is a bid with probability close to 1 . The realized range therefore overestimates the true daily variance by an amount equal to the spread $s$ times the number of intraday intervals $M$. Second, while infrequent trading does not affect the realized variance, it leads to a downward bias in the realized range. When the continuous underlying price process is only observed at discrete points in time, the observed high price during a given intraday interval underestimates the true maximum. Similarly, the observed low price overestimates the true minimum. Corrections for the infrequent trading bias in range-based volatility estimators have been proposed by Rogers and Satchell (1991) and Christensen and Podolskij (2007). Martens and Van Dijk (2007) suggest to deal with the "net" bias due to the combined effects of bid-ask bounce and infrequent trading on the realized range by applying a multiplicative bias-correction, see also Fleming et al. (2003). Specifically, the scaled realized range is defined by

$$
\left(\frac{\sum_{q=1}^{Q} R R_{t-q}}{\sum_{q=1}^{Q} R R_{t-q}^{\Delta}}\right) R R_{t}^{\Delta},
$$

where $R R_{t} \equiv R R_{t}^{1}$ is the daily range. Hence, the multiplicative correction factor is the ratio of the average daily range estimator and the average of the realized range over the past $Q$ days.

Although Martens and Van Dijk (2007) demonstrate that the multiplicative correction in (6) is quite effective in removing the bias in the realized range, here we consider an alternative, additive correction. This is motivated by observing that the presence of market microstructure effects is often represented by assuming that the observed $\log$ price $p_{i t}$ is equal to the efficient $\log$ price $p_{i t}^{*}$ plus an additive noise term $\varepsilon_{i t}$ :

$$
p_{i t}=p_{i t}^{*}+\varepsilon_{i t}
$$

where $\varepsilon_{i t}$ is assumed to have zero mean and variance $\sigma_{\varepsilon}^{2}$. In this set-up, the realized variance based on observed returns converges to the true integrated variance plus a bias term determined by the covariance between $p_{i t}^{*}$ and $\varepsilon_{i t}$ (which often is assumed to be zero, but see the discussion in Hansen and Lunde (2006)) and the noise variance $\sigma_{\varepsilon}^{2}$. This suggests that we may use an additive bias-correction, and define a scaled 
realized variance estimator as

$$
R V_{S, t}^{\Delta}=R V_{t}^{\Delta}+\frac{1}{Q}\left(\sum_{q=1}^{Q} R V_{t-q}-\sum_{q=1}^{Q} R V_{t-q}^{\Delta}\right)
$$

where $R V_{t} \equiv R V_{t}^{1}$ is the daily squared return. As discussed in Christensen et al. (in press), deriving consistent estimators of the integrated variance based on intraday high-low ranges is difficult, if not impossible in the presence of general microstructure noise as in (7). For that reason, we adopt a pragmatic approach and consider a realized range estimator with an additive bias-correction of the form (8), that is,

$$
R R_{S, t}^{\Delta}=R R_{t}^{\Delta}+\frac{1}{Q}\left(\sum_{q=1}^{Q} R R_{t-q}-\sum_{q=1}^{Q} R R_{t-q}^{\Delta}\right) .
$$

For covariance estimators based on intraday data, the most important microstructure effect is the occurrence of non-synchronous trading. Using returns or ranges over fixed intraday intervals results in covariance estimates that are biased towards zero. This so-called Epps (1979) effect becomes worse with increasing sampling frequency, and in the limit the standard realized covariance and realized co-range estimators converge to zero. Most of the recent proposals for alternative high-frequency covariance estimators are in fact attempts to fix the downward bias due to non-synchronous trading, see Hayashi and Yoshida (2005), Griffin and Oomen (2006), Zhang (2006), and Voev and Lunde (2007), among others. Here we limit ourselves to implementing the additive bias-correction discussed above for the realized co-range and realized covariance as well.

\section{Monte Carlo simulation}

In this section we investigate the performance of the realized co-range estimator in a controlled environment by means of Monte Carlo simulations. Throughout we compare the realized co-range estimator with the realized covariance estimator. Of particular interest are the effects of different microstructure frictions on the two estimators and the usefulness of the additive bias-correction described in the previous section. 


\section{Simulation design}

We simulate prices for two correlated assets for 24-hour days, assuming that trading takes place around the clock. For each day $t$, the initial prices for both assets are set equal to 1 , and subsequent $\log$ prices for asset $i=1,2$ are simulated using

$$
\log P_{i, t+k / K}^{*}=\log P_{i, t+(k-1) / K}^{*}+\varepsilon_{i, t+k / K}, \quad i=1,2, \quad k=1,2, \ldots, K,
$$

where $K$ is the number of prices per day. We simulate 100 prices per second, such that $K=8,640,000$, where price observations are equidistant and occur synchronously for the two assets. The shocks $\varepsilon_{i, t+k / K}$ are serially uncorrelated and normally distributed with mean zero and variance $\sigma_{i}^{2} /(D \cdot K)$, where $D$ is the number of trading days in a year, which we set equal to 250 . The annualized standard deviations $\sigma_{i}$ of the $\log$ price processes are set equal to 0.20 and 0.40 (20\% and 40\%) for assets 1 and 2 , respectively. The shocks $\varepsilon_{1, t+k / K}$ and $\varepsilon_{2, t+k / K}$ are contemporaneously correlated with correlation coefficient $\rho$, which we set equal to 0.50 , resulting in a covariance between the asset returns of 0.04 . We simulate prices for 5000 trading days in all experiments reported below.

We consider four different cases. Initially we aim to approximate the ideal situation with continuous trading and no market frictions and assume that all $K=8,640,000$ prices on a given day are observed. Second, we consider the effect of infrequent and non-synchronous trading. Infrequent trading is implemented by imposing that, given the price path obtained from (10), the probability to actually observe the price $P_{i, t+k / K}^{*}$ is equal to $p_{\mathrm{obs}}=1 /(100 \tau)$. Put differently, the price of each asset is observed on average only every $\tau$ seconds. Price observations for the two assets occur independently, such that in addition we observe prices nonsynchronously. Third, we consider the effects of bid-ask bounce. For this purpose we assume that transactions take place either at the ask price or at the bid price, which are equal to the true price plus and minus half the spread, respectively. Hence, the actually observed price $P_{i, t+k / K}$ is equal to $P_{i, t+k / K}^{*}+s / 2$ (ask) or $P_{i, t+k / K}^{*}-s / 2$ (bid), where $s$ is the bid-ask spread and $P_{i, t+k / K}^{*}$ is the true price obtained from (10). We assume that bid and ask prices occur equally likely and that the occurrence of bid and ask prices is independent across assets. In the fourth and final case, we consider the joint effects of infrequent and non-synchronous trading and bid-ask bounce by combining the specifications for these frictions as given above. 


\section{Computational details}

We assess the potential merits of using intraday ranges for measuring (daily) comovement by computing both the realized co-range and the realized covariance. To do so we divide the trading day into $\Delta$-minute intervals, which is referred to as the $\Delta$-minute frequency below. For example when $\Delta=5$ we divide the 24 -hour day into 288 five-minute intervals. For the realized covariance at this sampling frequency the cross-products of five-minute returns are summed to obtain the realized covariance at that frequency, as in (3). The realized co-range is computed using (5) as follows. For the two assets the high and low prices are computed per five-minute interval and the resulting five-minute squared ranges are summed to obtain the realized ranges for the day, as in (2). To obtain the realized range of a portfolio consisting of the two assets, we first compute the intraday prices of an equally-weighted portfolio setting $\lambda_{i}=0.5, i=1,2$, and assuming continuous rebalancing throughout the day. ${ }^{3}$ Note that in the case of synchronous price observations for the two assets we can compute exact portfolio prices at each instant. In case of non-synchronous trading the portfolio price is updated each time a new price for one of the two assets occurs, combining this with the most recently observed (hence stale) price for the other asset. Second, the portfolio prices are used to compute the corresponding realized range in the usual way. This is then combined with the realized ranges for the two individual assets using (5) to compute the realized co-range. We also consider the bias-corrected versions of the realized covariance and the realized corange, computed according to (8) and (9), respectively. ${ }^{4}$ In the experiments with non-trading and bid-ask bounce, the characteristics of these microstructure frictions are identical for all trading days, such that in principle we could use a large number of trading days $Q$ to compute the additive adjustment factor to fully explore the merits of the bias-adjustment procedure. In practice, however, the characteristics of microstructure noise are likely to change over time and a smaller value of $Q$

\footnotetext{
${ }^{3}$ We perform a sensitivity analysis on the portfolio weights by experimenting with $\lambda_{1}=$ $0.1,0.3,0.5,0.7,0.9$. We find that the choice of portfolio weights has only minor influence on the efficiency (RMSE) of the co-range estimator. Detailed simulation results are available upon request.

${ }^{4}$ We also considered an alternative bias-correction for the realized co-range, by computing it according to (5) but using the scaled realized ranges as defined in (9). This "indirect" bias-correction results in qualitatively and quantitatively similar results (which are available upon request) as the "direct" bias-correction reported in this section.
} 
seems more appropriate. We therefore set $Q=66$ throughout the simulations. The sensitivity of the results with respect to the value of $Q$ is discussed in more detail below. For each selected frequency we compute the mean and Root Mean Squared Error (RMSE) for the various estimators of the assets' covariation, taken over 5000 simulated trading days.

\section{Case I: Continuous trading and no bid-ask bounce}

Results for the case of continuous trading and no bid-ask bounce are presented in Table 1.

\section{- insert Table 1 about here -}

As expected, in this case the RMSE of the realized co-range is always substantially lower than that of the realized covariance at the same frequency. In fact, for all but the very highest sampling frequencies the ratio of the RMSEs is close to $\sqrt{5}$, which is the ratio of the standard deviations of the daily squared returns and daily ranges. Hence, the same efficiency factor seems to apply to the intraday rangeand return-based measures of covariation examined here. The slight loss in relative efficiency of the realized co-range at the highest sampling frequencies is due to the downward bias it experiences when the underlying price ranges are computed over very short intervals, as shown in the second column of Table 1. This is inherent to the nature of the high-low range: In case the price path is not observed continuously (in this case we observe 'only' 6000 prices per minute) the observed minimum and maximum over- and underestimate the true high and low prices, respectively, such that the observed range underestimates the true range. We investigate the effects of infrequent trading in more detail below.

In the last row of this table, labeled $\Delta=1440$ minutes, the realized co-range actually is the daily co-range suggested by Brandt and Diebold (2006), while the realized covariance equals the cross-product of daily returns. The RMSE of the daily co-range is substantially lower at 4.044, compared to 8.830 for the cross-product of daily returns. Similar to the findings of Brandt and Diebold (2006), and Martens and Van Dijk (2007), the realized covariance requires the 4- to 6-hour (240 to 360 minutes) frequency to achieve an RMSE that is comparable to the daily co-range. 


\section{Case II: Infrequent and non-synchronous trading, no bid-ask bounce}

Table 2 shows the results when infrequent trading occurs, such that the price is observed on average only every $\tau=12$ seconds. $^{5}$

\section{- insert Table 2 about here -}

The results for the realized co-range in Table 2 (column 1) show that the RMSE first decreases when increasing the sampling frequency up to 20 minutes. Then it increases again for higher frequencies because the larger bias due to non-trading (and hence underestimating the range for each intraday interval) then outweighs the reduction in the standard deviation of the estimates. The realized covariance estimator is not affected by infrequent trading ${ }^{6}$ but does suffer from non-synchronous trading in terms of a downward bias. As a result, at the 15-minute frequency the realized co-range still is a more accurate measure of co-movement than the corresponding realized covariance, but at higher frequencies the realized covariance has a lower RMSE than the realized co-range. Of course the exact frequency at which one estimator improves over the other will depend on the trading intensity. For example, when transaction prices are observed once per second on average every second the realized co-range improves over the realized covariance up to the five-minute frequency. The results for $R R C O V_{S, t}^{\Delta}$ in Table 2 demonstrate that bias-correcting the realized co-range eliminates the bias to a large extent but not completely, which is due to the fact that the daily co-range also is somewhat biased downward due to the infrequent and non-synchronous trading. The bias-adjustment reduces the RMSE of the realized co-range considerably, such that $R R C O V_{S, t}^{\Delta}$ is more accurate than the realized covariance for all sampling frequencies except $2-5$ minutes.

\section{Case III: Continuous trading and bid-ask bounce}

Next, we consider the effects of bid-ask bounce. As in Brandt and Diebold (2006), we set the spread $s$ equal to 0.0005 (or $0.05 \%$ of the starting price of 1 ). ${ }^{7}$

\footnotetext{
${ }^{5}$ Results for other trading frequencies are summarized at the end of this section, with details being available upon request.

${ }^{6}$ This becomes evident from unreported results from simulations with infrequent but simultaneous trading for the two assets. Detailed results are available upon request.

${ }^{7}$ Results for other magnitudes of the bid-ask spread are summarized at the end of this section, with details being available upon request.
} 


\section{- insert Table 3 about here -}

The results in Table 3 illustrate that, as expected, the realized co-range suffers from a pronounced upward bias, which gets worse as the sampling frequency increases. The bias in the realized co-range is caused by the fact that with continuous price observations the observed range for the individual assets will overestimate the true ranges by a quantity close to the spread, as the maximum price will be an ask and the minimum price will be a bid with probability close to 1 . For the equallyweighted portfolio, the true range is overestimated by the bid-ask spread as well when trading is continuous. Hence, the net effect on the realized co-range in (5) is an upward bias. The realized covariance is not affected by bid-ask spread, which also is conform expectations. In this particular parameter configuration the realized co-range outperforms the realized covariance up to the 45-minute frequency. For higher sampling frequencies the RMSE of the realized covariance is smaller. Biascorrecting the realized co-range works remarkably well, in the sense that the bias is removed completely and the RMSE values are almost brought back to the original level observed for $R R C O V_{S, t}^{\Delta}$ in the ideal case without bid-ask bounce shown in Table 1. For sampling frequencies of 10 minutes or lower, the RMSE of the bias-corrected realized co-range is smaller than the RMSE of the realized covariance.

\section{Case IV: Infrequent and non-synchronous trading and bid-ask bounce}

In reality, bid-ask bounce, infrequent trading and non-synchronous trading of course are jointly present. We examine this situation by combining the previous specifications for these frictions. Results for this experiment are shown in Table 4.

\section{- insert Table 4 about here -}

The realized co-range still suffers from an upward bias, but it is of a considerably smaller magnitude than in the case of bid-ask bounce only due to the off-setting negative bias induced by infrequent and non-synchronous trading. As a result, the realized co-range now has a lower RMSE than the realized covariance at all sampling frequencies. The overall minimum RMSE for the realized co-range is obtained at the 2-minute sampling frequency and equals 0.205. For the realized covariance the optimal frequency is the 3-minute frequency for which the RMSE is 0.551. Note that in this particular setting, where the different biases affecting the realized co-range 
approximately cancel out, bias-adjustment is not attractive. Although the mean of $R R C O V_{S, t}^{\Delta}$ is closer to the true covariance of 4 , the variance increases considerable due to the bias-adjustment such that the RMSE increases compared to the 'raw' realized co-range $R R C O V_{t}^{\Delta}$. Finally, in Tables and 2 and 4, we also observe that bias-correcting the realized covariance is never worthwhile, as apparently the reduction in bias does not outweigh the increase in variance, such that the RMSE of $R V C O V_{S, t}^{\Delta}$ is always substantially higher than the RMSE of the 'raw' realized covariance $R V C O V_{t}^{\Delta}$.

\section{Sensitivity analysis: Trading frequency, spread size, bias correction}

Whether or not the realized co-range improves upon the realized covariance, and whether or not bias-adjustment is appropriate of course depends on the (relative) magnitudes of the market microstructure frictions. For that reason, Table 5 provides an overview of the different covariance estimators for different trading frequencies $\tau$, ranging from 2 to 60 seconds, and different bid-ask spreads $s$, ranging from 0 to 0.00075. For each combination of $\tau$ and $s$, the table shows the optimal sampling frequency for the four covariance estimators, along with the corresponding RMSE and mean. The covariance estimator that achieves the lowest RMSE for a given combination of $\tau$ and $s$ is shown in italics. The patterns that can be observed in this table are as expected. First, in the absence of bid-ask bounce (first column, $s=0$ ), the realized covariance estimator performs best when prices are observed relatively frequently, up to once per 15 seconds on average. This is due to the downward bias which only affects the realized co-range. However, when trading is less frequent, the adjusted realized co-range achieves the lowest RMSE.

\section{- insert Table 5 about here -}

Second, in the presence of bid-ask bounce, the unadjusted realized co-range performs best for those combinations of $\tau$ and $s$ for which the downward bias due to infrequent trading and the upward bias due to bid-ask bounce approximately cancel. This is the case for $s$ equal to 0.00025 and $\tau$ equal to 3 to 6 seconds, for $s$ equal to 0.0005 and $\tau$ equal to 10 to 20 seconds, and for $s$ equal to 0.00075 and $\tau$ equal to 20 to 40 seconds. Hence the higher the spread (upward bias) the less frequent trading should be (downward bias) to have the two biases offset each other. Note that in 
financial markets there is indeed a strong negative relationship between spread and trading frequency: The less an asset trades, the higher the spread. Hence one would expect that these simulated cases will arise in actual data, and this will favor the realized co-range.

Third, when trading occurs relatively frequently, such that the upward bias dominates, the realized covariance is preferred. On the other hand, when trading occurs relatively infrequently, such that the downward bias dominates, the adjusted realized co-range renders the lowest RMSE values. Note that for the largest spread considered here, $s=0.00075$, the adjusted realized co-range in fact also outperforms the realized covariance for 'frequent' trading at once per 10-15 seconds. Unreported results for even higher values of $s(0.001)$ show that in that case, the bias-corrected realized co-range dominates for all trading frequencies.

Fourth, Table 5 shows that for the bias-corrected realized covariance and realized co-range, apart from a few exceptions, the highest possible sampling frequency leads to the lowest RMSE. This is not surprising given that sampling more frequently leads to a lower standard deviation of the covariance estimators, which in the absence of bias also implies a lower RMSE. For the unadjusted realized covariance, we observe that less frequent trading always leads to less frequent sampling to achieve the lowest possible RMSE. For the realized co-range this only holds in the absence of bid-ask bounce. When bid-ask bounce does occur next to infrequent and non-synchronous trading, it sometimes pays off to sample 'too frequently', such that the positive and negative biases approximately cancel.

Finally, as noted in the previous section, the number of trading days $Q$ used to compute the correction factor for $R R C O V_{S, t}^{\Delta}$ is a crucial choice to be made. If the trading intensity and the spread are constant over time, $Q$ may be set large in order to gain accuracy. On the other hand, when the magnitude of these microstructure frictions varies over time, only the recent price history should be used and $Q$ should be set fairly small. Figure 1 shows the RMSE of the bias-corrected realized co-range for the experiment with infrequent trading as a function of $Q$, with the rightmost point of each line showing the RMSE for $Q=5000$ as given in Table 4 . The RMSE monotonically declines as $q$ increases, but the largest gains occur up to $Q=100$, beyond which the RMSE more or less stabilizes. Hence, our choice of $Q=66$ does not seem unreasonable. Also note that the reduction in RMSE due to increasing $Q$ 
is largest for higher sampling frequencies.

\section{- insert Figure 1 about here -}

Concluding, the simulation experiments quite convincingly demonstrate the potential of the realized co-range as a measure of daily co-movement among assets. In case of continuous trading and no market frictions it always improves upon the realized covariance when using the same sampling frequency. In reality trading is non-continuous and non-synchronous and observed prices are bid and ask prices. Although the realized co-range suffers from biases due to each of these market frictions, in realistic settings the downward bias due to infrequent and non-synchronous trading may approximately cancel against the upward bias due to bid-ask bounce. Hence even in the presence of market microstructure effects, the realized co-range is likely to outperform the realized covariance, which only is affected negatively by non-synchronous trading. In addition, bias-correcting the realized co-range with the recent historical average (relative) level of the daily co-range is an effective procedure to restore the efficiency of the realized co-range in case the different biases do not offset each other.

\section{Empirical application}

In this section we study the empirical usefulness of the realized co-range by evaluating its performance in a dynamic volatility timing strategy, adopting the framework developed by Fleming et al. (2001, 2003). We consider an investor who uses conditional mean-variance analysis for constructing a portfolio with minimum variance given a specific target return. The portfolio is dynamic in the sense that optimal weights are re-computed daily. The investor follows a volatility-timing strategy, as the portfolio weights are based on a forecast of the conditional covariance matrix while expected returns are held constant. We assess the merits of using the realized co-range to construct these forecasts, relative to the realized covariance. We also include their daily counterparts in the comparison.

\subsection{Data}

Following Fleming et al. (2003), we consider portfolios consisting of stocks, bonds and gold. We assume that the investor trades futures contracts to construct her 
portfolio, to avoid short-selling restrictions and to save on transactions costs. We obtain intraday transactions data for futures contracts on stocks (S\&P500, Chicago Mercantile Exchange, 8:30 am - 15:15 pm), US T-bonds (Chicago Board of Trade, 8:00 am - 14:00 pm) and gold (New York Mercantile Exchange, 7:20 am - 13:30 $\mathrm{pm}^{8}$ ), for the period from January 3, 1984 to December 31, $2006 .^{9}$

We exclude all days on which any of the three markets is closed, leaving a total of 5592 days of high-frequency data on which the three contracts traded simultaneously. Our sample period includes the October 19, 1987 stock market crash and September 11, 2001. The bid-ask spreads on the three futures contracts were much higher in the days following the October 1987 crash, for this reason we follow Fleming et al. (2003) by replacing the high-frequency covariance estimators by their daily counterparts for the period October 19 to 30, 1987. We exclude the days following September 11, 2001 as markets were closed. The very large negative overnight return for the September 11-17 period is excluded as well.

The high-frequency data only covers the part of the day during which futures markets are open. Fleming et al. (2003) and De Pooter et al. (in press) add the cross-product of overnight returns to the realized covariance estimate in order to obtain a measure of the covariation during a complete 24-hour day. Both studies find that incorporating overnight returns adds information and improves the performance of the volatility timing strategy. We choose not to include the overnight returns, however, as adding the same overnight returns to the realized co-range and realized covariance estimators would diminish the difference between these estimators and, presumably, any differences in their overall performance. Since both estimators aim to estimate the integrated covariation they are already expected to behave similarly to a large extent.

At any given day we use prices of the nearby futures contract in each market and roll to the second nearby contract for gold and bonds when the nearby contract enters its final month. For stocks we roll to the second nearby contract at 13:30 pm on the 11th trading day in the final month. We assume that the investor updates her portfolio daily at 13:30 pm. For the daily return series that is used to evaluate the investment strategy, we use the last transaction prices occurring before that time.

\footnotetext{
${ }^{8}$ All trading hours are standardized to the EST time zone

${ }^{9}$ The data is obtained from Tick Data, http://www.tickdata.com/.
} 
In case a contract is rolled forward on day $t+1$ we use the price at 13:30 pm on day $t$ of the 'new' contract to compute the daily return for day $t+1$.

The intraday time grid spans the period 7:20 am - 13:30 pm, where the 13:30 closing time is motivated by the closing time of the trade in gold futures. We adopt the popular five-minute frequency for computing the realized (co-)range and realized (co-)variance. To compute the five-minute returns that are used in the latter estimator, we use the last transaction prices in each intraday interval. For the volatility estimates based on the realized variances and realized ranges we use the complete trading period. For the covariance estimates, we adopt the following two-step procedure of Fleming et al. (2003). First, we construct volatilities and covariances for the contemporaneous time span of intraday data, from which we back out estimates of the correlations among the three assets. Second, we convert these correlations back into covariances by using the realized variances and realized ranges for the whole day.

\section{- insert Table 6 about here -}

Table 6 displays summary statistics for the annualized daily returns and the high-frequency volatility and correlation estimates. For all three assets we find that the mean of the realized range is smaller than the mean of the realized variance, suggesting that infrequent trading is more important than bid-ask bounce for these futures contracts, such that the realized range is biased downward. As expected, the standard deviation of the realized range turns out to be substantially smaller than that of the realized variance. This carries over to the multivariate case, where the standard deviation of the realized correlations estimated by means of the co-range is smaller than the standard deviation of the correlations implied by the realized covariance. This indicates that the realized co-range is less noisy than the realized covariance. Graphical support for this result is illustrated in Figure 2. Although both estimators provide similar correlation patterns, the daily correlations based on the realized covariance are more volatile and show much more spikes than the correlations based on the realized co-range.

\section{- insert Figure 2 about here -}




\subsection{Volatility timing}

The investor uses conditional mean-variance analysis for forming a portfolio with minimum variance given a specific target return. The portfolio weights $w_{t}$ follow from solving the standard quadratic programming problem, where the portfolio variance $\left(\sigma_{p}^{2}=w_{t}^{\prime} \Sigma_{t} w_{t}\right)$ is minimized subject to a target portfolio return $\left(\mu_{p}=w_{t}^{\prime} \mu\right)$. The resulting minimum-variance weights are given by

$$
w_{t}=\frac{\mu_{p} \Sigma_{t}^{-1} \mu_{t}}{\mu_{t}^{\prime} \Sigma_{t}^{-1} \mu_{t}},
$$

where $\Sigma_{t}$ is the conditional covariance matrix for day $t$ and $\mu_{t}$ is the vector of conditional expected returns. In general, these unrestricted portfolio weights do not add up to one. We include a risk-free asset (cash) with weight $1-w_{t}^{\prime} \iota$, where $\iota$ is a vector of ones, which makes the portfolio fully invested. Given that we want to focus on differences in the investment strategy's performance through the dynamics of $\Sigma_{t}$, we keep the expected returns constant by setting $\mu_{t}=\mu$, where $\mu$ is taken to be the vector of full-sample mean returns, see line 1 of Table 6. Following Fleming et al. (2003), we set the annualized target portfolio return $\mu_{p}=10 \%$ and assume a constant risk-free rate $r_{f}=6 \%$.

Implementing the volatility timing strategy requires an estimate of the conditional covariance matrix $\Sigma_{t}$ in (11). Following Fleming et al. (2003), we use backward-looking 'rolling' estimators using an exponential weighting scheme, motivated by the work of Foster and Nelson (1996) and Andreou and Ghysels (2002). The general expression for the rolling daily conditional covariance estimator for day $t$ is given by

$$
\widehat{\Sigma}_{t}=\exp (-\alpha) \widehat{\Sigma}_{t-1}+\alpha \exp (-\alpha) V_{t-1},
$$

where $\alpha$ is the decay parameter and $V_{t-1}$ is an estimate of the realized covariance matrix on day $t-1$. We expect that the decay parameter decreases with the level of noise in $V_{t-1}$. Our main interest lies in the performance of the volatility timing strategy when using the realized (co-)range in (2) and (5) to construct $V_{t-1}$, compared to using the realized (co-)variance in (1) and (3). In order to reduce the effects of microstructure noise, we follow Fleming et al. (2003) and employ the biascorrected versions of these estimators, as discussed in Section 2.2. For the additive bias-correction we set $Q=22$, that is, we use a shorter history compared to the simulations in Section 3. This is motivated by the fact that the rolling estimator in (12) 
'smooths' the realized estimators, which also reduces the effects of noise to a certain extent. To gauge the benefits of using intraday data, we also include estimators of $V_{t-1}$ based on daily (close-to-open) returns and daily (co-)ranges.

The decay parameter $\alpha$ in (12) is estimated by maximizing the log-likelihood function corresponding with the model

$$
r_{t}=\mu+\widehat{\Sigma}_{t}^{\frac{1}{2}} z_{t}
$$

where $\mu$ is the vector of daily expected returns, $\widehat{\Sigma}_{t}$ is the conditional covariance matrix obtained from (12), and $z_{t} \sim N I D(0, I)$. The likelihood function is maximized using the complete sample period, as in Fleming et al. (2003), although we use the first year of our sample as a burn-in period for the (co)variance dynamics. ${ }^{10}$ The maximum-likelihood procedure results in a decay parameter of 0.082 for the daily co-range and 0.0298 for the daily covariance. For the intraday based covariation estimators we find decay parameters equal to 0.064 and 0.062 for the bias-corrected realized co-range and realized covariance, respectively. The daily co-range has a much larger decay parameter than the daily covariance estimator, this suggests that the co-range is less noisy.

The daily portfolio weights (11) are based on the one day ahead forecast of the bias-corrected rolling covariance matrix estimator in (12). The daily realized returns of the portfolio are obtained as $w_{t}^{\prime} r_{t}$, where $r_{t}$ is the vector of daily returns. Below we report the annualized average portfolio returns, volatility and the Sharpe Ratio (SR). Furthermore we also keep track of the turnover of the portfolio using $T O_{t}=\left|w_{t}-w_{t-1}\right|^{\prime} \iota$ to provide insight into the transaction costs arising from daily rebalancing the portfolio. In addition, we compute the break-even costs, that is, the level of transaction costs that would reduce the profitability of the investment strategy to zero. ${ }^{11}$

\footnotetext{
${ }^{10}$ This burn-in period is excluded from all performance evaluations below.

${ }^{11}$ Here we deviate from Fleming et al. (2003) who use a quadratic utility function to assess the economic value of volatility timing using realized covariances compared to daily covariances. The reason we do not use such utility function is because it is based on the mean and volatility of the portfolio returns. Tables 7 and 8 illustrate that the mean portfolio return and the volatility of the portfolio are very similar for the realized covariance and realized co-range. However, the levels of noise in the correlations implied by the realized covariance and realized co-range are different, see Figure 4 and Table 6, and for this reason there exists a substantial difference in turnover in both portfolio weights, see Table 7 . Therefore we choose to compare both estimators in terms of break-even transaction costs.
} 


\subsection{Empirical results}

The rolling estimators based on the realized range and realized variance estimators, as well as their daily counterparts, result in similar volatility dynamics, as visualized in Figure 3. The main difference appears to be that the range-based estimators in panels (a) and (c) show higher levels of stock volatility during periods of turmoil such as October 1987 and the Russia crisis in 1998.

\section{- insert Figure 3 about here -}

Larger differences between range-based and return-based rolling estimators are found in the behavior of the correlations, visualized in Figure 4. Although the general correlation patterns appear to be similar, the correlations based on the realized covariance or daily covariance are larger in absolute value and tend to fluctuate more widely than the range-based correlations. The relative stability of the rangebased correlations may in fact be an advantage. Not only is an investor likely to be reluctant to base her investment decisions on very volatile correlation estimators, a more stable correlation estimate will also result in less day-to-day fluctuations in the portfolio weights, and hence lower transaction costs.

\section{- insert Figure 4 about here -}

The results in Table 7 illustrate that over the whole sample (1985-2006) the performance of the volatility timing strategy based on the bias-corrected rolling realized co-range and realized covariance estimators is very close. The realized corange earns a slightly higher average return of $9.4 \%$ compared to $9.3 \%$ for the realized covariance. As the portfolio volatilities are the same at $7.2 \%$ annually, this results in Sharpe ratios that are almost identical and equal to 1.31 and 1.30, respectively.

\section{- insert Table 7 about here -}

Although the strategies based on the realized co-range and realized covariance result in a similar performance before transaction costs, the dynamics of the underlying portfolios are quite different. The portfolio weights illustrated in Figure 5 demonstrate that the realized co-range yields weights that are much less volatile 
than the realized covariance. The turnover generated by the realized co-range portfolio is equal to 5.9, substantially smaller than that of the realized covariance at 9.5. This results in break-even transaction cost levels of 159.8 and 98.4 basis points for the realized co-range and for the realized covariance, respectively. Hence, the realized co-range outperforms the realized covariance substantially by more than 60 basis points.

\section{- insert Figure 5 about here -}

Table 7 illustrates that the main results are similar in smaller samples. The realized co-range and realized covariance provide similar risk-return characteristics and therefore identical Sharpe ratios. The turnover in the realized co-range portfolio weights is substantially smaller than that of the realized covariance in each of the subsamples. This results in a better performance of the realized co-range in terms of break-even transaction costs.

Consistent with other high-frequency data studies, Table 7 illustrates that the use of intraday data leads to better estimates than the use of daily data. This holds for both return- and range-based estimators. When we compare the performance of the daily covariance with the realized covariance sampled using 5-minute intervals we see that more precise (co)variance estimates increase the average return by 20 basis points from $9.1 \%$ to $9.3 \%$. The risk of the portfolio, as measured by the volatility of the portfolio returns, decreases from $7.4 \%$ to $7.2 \%$, which is equal to the risk of the daily co-range portfolio. The turnover decreases from 10.2 to 9.5 , leading to slightly higher break-even transaction costs, an increase of almost 10 basis points per annum.

For the co-range the use of intraday data is even more profitable. ${ }^{12}$ The daily corange achieves an average portfolio return of $8.8 \%$, compared to $9.4 \%$ for the realized co-range. The return difference of about 60 basis points comes at the same level of portfolio risk, such that the Sharpe ratio increases from 1.23 to 1.31 when switching from the daily co-range to the realized co-range. The most notable difference occurs in terms of turnover, which is substantially larger for the daily co-range (17.1) than

\footnotetext{
${ }^{12}$ This result is corroborated by Table 8 which summarizes the results for equal decay parameters. The larger profitably is not caused by the fact that the realized co-range has a smaller decay parameter than the daily co-range, when we fix the decay parameter, then the realized co-range outperforms the daily co-range.
} 
for the realized co-range. This leads to larger transaction costs for the daily corange, and results in a large difference in break-even transaction costs of more than 100 basis points (51.6 compared to 159.8).

Concluding, the use of the realized co-range in a volatility timing investment strategy has appealing economic advantages, especially when transaction costs are taken into account. The more precise covariance estimates that are obtained with high-frequency intraday ranges result in a more stable portfolio with smaller turnover and, thus, higher break-even transaction costs.

\subsection{Sensitivity analysis for the decay parameter}

The empirical results described above are based on decay parameters that maximize the log-likelihood function of the GARCH-type model in Equation (13). For several reasons it is interesting to examine the sensitivity of the volatility timing results for the choice of $\alpha$.

First, the results of Fleming et al. (2003) and De Pooter et al. (in press) illustrate that the decay parameters that maximize the statistical fit do not necessarily provide the best economic performance in a volatility timing strategy. Second, in the forecasts obtained from Equation (12), the decay rate $\alpha$ determines the weight put on the 'backward looking' rolling estimator, which equals $\exp (-\alpha)$, and the weight put on the innovation term, $\alpha \exp (-\alpha)$. When $\alpha$ is small this indicates that the estimator requires a large amount of 'smoothing' because it is noisy, whereas a large $\alpha$ indicates less smoothing. When we use a small decay parameter for the realized covariance and realized co-range, they are expected to provide similar results as the noise is 'smoothed' out to a large extent. ${ }^{13}$ The maximum-likelihood estimates for the decay parameters are relatively small, which implies a large amount of smoothing and therefore small differences in performance. Pinning down $\alpha$ at larger values for both estimators is a good test case as it allows us to assess the quality of the innovation term $V_{t-1}$ in Equation (12). Doing so we expect to find larger differences in the average portfolio returns and levels of risk corresponding to the use of the realized covariance or realized co-range in a volatility timing strategy. Third, we expect the decay parameter to have an important impact on turnover as a large

\footnotetext{
${ }^{13}$ We thank Torben Andersen for providing this insight.
} 
decay parameter implies a large weight on the most recent innovation and therefore more turnover in the portfolio weights. Fixing the decay rates enables a more fair comparison in terms of the break-even transaction costs.

Table 8 summarizes the empirical results for the competing rolling variancecovariance estimators over the 1985-2006 period using a grid of decay parameters ranging from 0.01 to 0.175 . Before taking into account turnover and transaction costs the performance of the realized co-range and realized covariance is similar for small and intermediate decay rates $(\alpha=0.01$ to 0.10$)$. For example, using a decay rate of 0.05 results in identical levels of risk $(7.2 \%)$ and return $(9.4 \%)$ and therefore approximately equal Sharpe ratios (1.302 and 1.308).

However, in the test case for larger decay rates, where more weight is put on the most recent estimate, the performance of the realized covariance deteriorates while the performance of the realized co-range remains robust. For example, when we use a decay rate of 0.15 then the realized co-range achieves a SR equal to 1.29 while the SR of the realized covariance decreases to 1.15. At the daily sampling frequency the co-range also seems more robust to the choice of decay parameter than the daily covariance estimator. Although the performance of the daily co-range worsens for large decay rates, the decrease in performance is substantially smaller than that of the daily covariance. Before taking into account turnover and transaction costs, the daily co-range outperforms the daily covariance for the whole range of decay rates, and it competes with the realized covariance when using decay rates larger than or equal to 0.15 . The realized co-range outperforms the daily co-range regardless of the decay rate. The difference is more emphasized for large decay parameters. The risk-return characteristics of the realized co-range are substantially better as expressed by the difference in Share ratio which increases with the amount of weight put on the most recent covariance estimate.

When we compare the turnover generated by the realized covariance and realized co-range, it turns out that the realized co-range decreases the turnover by $33 \%$ for a decay parameter of 0.01 , up to a reduction of $62 \%$ for a decay parameter of 0.15 . Using the realized covariance instead of the daily covariance reduces turnover by about $35 \%$ for large decay rates and up to $55 \%$ for small and intermediate decay parameters. A similar comparison of the realized co-range with its daily counterpart shows a reduction in turnover of about $50 \%$ to almost $60 \%$, for small and large decay 
rates, respectively.

From the sensitivity analysis we conclude that the realized co-range is more robust to the choice of decay parameter than the realized covariance, the daily covariance and the daily co-range. The smaller turnover and better break-even transaction costs of the realized co-range do not depend on the decay rate but they are caused by more precise estimates of the covariance matrix. When pinning down the decay rate, the realized co-range never has a worse performance than the realized covariance before measuring turnover and costs. If we do take into account turnover and compute break-even transaction costs, then the realized co-range outperforms the realized covariance and the two daily estimators. When the weight on recent estimates is large, then the realized co-range also achieves a better performance than the realized covariance in terms of risk and returns and therefore results in higher Sharpe ratios in the volatility timing strategy.

\section{Conclusion}

We have extended range-based covariance estimation with a novel high-low range estimator based on intraday data. The covariance between two assets is backed out from their individual variances and the variance of a portfolio of the two assets, where the realized range is used to estimate each of these variances. Due to the relative efficiency of range-based volatility measures, the realized co-range provides a considerably more accurate measure of covariation than the realized covariance, which uses cross-products of intraday returns. The realized co-range continues to have attractive properties in the presence of market microstructure noise due to bidask bounce, infrequent trading and non-synchronous trading. A key advantage of the co-range is that the upward bias due to bid-ask bounce and the downward bias due to infrequent and non-synchronous trading partially offset each other. Although the realized covariance is also downward biased due to infrequent trading, it is not biased due to bid-ask bounce. For empirically plausible levels of bid-ask bounce and non-synchronous trading we indeed find that the realized co-range improves over the realized covariance. In case the different biases do not offset each other, biascorrecting the realized co-range with the recent historical average (relative) level of the daily co-range is an effective procedure to restore the efficiency of the realized 
co-range.

In the empirical study for S\&P500, bond and gold futures, we find that in Fleming et al.'s (2003) volatility timing strategy the realized co-range and realized covariance provide similar results before taking into account transaction costs. The level of noise in the correlations implied by the realized co-range is substantially smaller than that of the realized covariance, leading to smaller variation in the portfolio weights whilst still providing a similar risk-return profile. After taking into account transaction costs, the realized co-range outperforms the realized covariance by about 60 basis points per annum when the decay parameters are estimated by maximum-likelihood. The reason behind the similar risk-return profile is that for forecasting covariances both the realized co-range and the realized covariance use small decay parameters putting a lot of weight on older covariance estimates to smooth noise. If larger decay parameters are used, putting more emphasis on the covariance estimates of the most recent day, then the risk-return profile of the co-range becomes superior.

In future research it will be interesting to study the theoretical properties of the co-range. In addition alternative estimators based on intraday highs and lows and alternative bias-corrections could be explored, similar to existing studies on the realized covariance. Finally the empirical analysis could be applied to individual stocks, exhibiting more noise, and different sampling frequencies could be tested. 


\section{References}

Aït-Sahalia, Y., P. Mykland and L. Zhang (2005), How Often to Sample a ContinuousTime Process in the Presence of Market Microstructure Noise, Review of Financial Studies 18(2), 351-416.

Andersen, T. G., T. Bollerslev, P. F. Christoffersen and F. X. Diebold (2006), Volatility and Correlation Forecasting, in Graham Elliott, Clive W. J. Granger and Allan Timmermann (eds.), Handbook of Economic Forecasting, Elsevier, North-Holland, pp. $777-878$.

Andersen, T.G., T. Bollerslev, F.X. Diebold and P. Labys (2001), The Distribution of Realized Exchange Rate Volatility, Journal of the American Statistical Association 96(453), 42-55.

Andersen, Torben G., Tim Bollerslev, Francis X. Diebold and Paul Labys (2003), Modeling and Forecasting Realized Volatility, Econometrica 71(2), 579-625.

Andreou, Elena and Eric Ghysels (2002), Rolling-Sample Volatility Estimators: Some New Theoretical, Simulation and Empirical Results, Journal of Business and Economic Statistics 20(3), 363-376.

Awartani, B., V. Corradi and W. Distaso (2007), Testing Market Microstructure Effects with an Application to the Dow Jones Industrial Average, Working paper, Imperial College London.

Bandi, F. M. and J. R. Russell (2006), Separating Microstructure Noise from Volatility, Journal of Financial Economics 79(3), 655-692.

Bandi, F. M. and J. R. Russell (in press), Microstructure Noise, Realized Variance, and Optimal Sampling, Review of Economic Studies.

Bandi, F. M., J. R. Russell and Y. Zhu (in press), Using High-Frequency Data in Dynamic Portfolio Choice, Econometric Reviews.

Barndorff-Nielsen, O. E. and N. Shephard (2002), Econometric Analysis of Realized Volatility and Its Use in Estimating Stochastic Volatility Models, Journal of the Royal Statistical Society Series B 64(2), 253-280.

Barndorff-Nielsen, O. E. and N. Shephard (2004), Econometric Analysis of Realized Covariation: High Frequency Based Covariance, Regression, and Correlation in Financial Economics, Econometrica 72(3), 885-925.

Brandt, M. W. and F. X. Diebold (2006), A No-Arbitrage Approach to Range-Based Estimation of Return Covariances and Correlations, Journal of Business 79(1), 6174 .

Christensen, K. and M. Podolskij (2007), Realized Range-Based Estimation of Integrated Variance, Journal of Econometrics 141(2), 323-349.

Christensen, K., M. Podolskij and M. Vetter (in press), Bias-Correcting the Realized Range-Based Variance in the Presence of Market Microstructure Noise, Finance and Stochastics.

De Pooter, M., M. Martens and D. Van Dijk (in press), Predicting the Daily Covariance Matrix for S\&P 100 Stocks Using Intraday Data - But Which Frequency to Use?, Econometric Reviews.

Epps, T. W. (1979), Comovements in Stock Prices in the Very Short Run, Journal of the American Statistical Association 74(366), 291-298. 
Fleming, J., C. Kirby and B. Ostdiek (2001), The Economic Value of Volatility Timing, Journal of Finance 56(1), 329-352.

Fleming, J., C. Kirby and B. Ostdiek (2003), The Economic Value of Volatility Timing Using "Realized" Volatility, Journal of Financial Economics 67(3), 473-509.

Foster, D. P. and D. B. Nelson (1996), Continuous Record Asymptotics for Rolling Sample Variance Estimators, Econometrica 64(3), 139-174.

Griffin, J. E. and R. C. A. Oomen (2006), Covariance Measurement in the Presence of Non-Synchronous Trading and Market Microstructure Noise, working paper.

Hansen, P. R. and A. Lunde (2006), Realized Variance and Market Microstructure Noise, Journal of Business and Economic Statistics 24(2), 127-218.

Hayashi, T. and N. Yoshida (2005), On Covariance Estimation of Non-Synchronously Observed Diffusion Processes, Bernoulli 11(2), 359-379.

Martens, M. and D. Van Dijk (2007), Measuring Volatility With the Realized Range, Journal of Econometrics 138(1), 181-207.

McAleer, M. and M. C. Medeiros (in press), Realized Volatility: A Review, Econometric Reviews.

Oomen, R. C. A. (2005), Properties of Bias-corrected Realized Variance under Alternative Sampling Schemes, Journal of Financial Econometrics 3(4), 555-577.

Parkinson, M. (1980), The Extreme Value Method for Estimating the Variance of the Rate of Return, Journal of Business 53(1), 61-65.

Rogers, L. C. G. and S. E. Satchell (1991), Estimating Variance From High, Low and Closing Prices, Annals of Applied Probability 1(4), 504-512.

Sheppard, N. (2005), Realized Covariance and Scrambling, working paper.

Voev, V. and A. Lunde (2007), Integrated Covariance Estimation Using High-Frequency Data in the Presence of Noise, Journal of Financial Econometrics 5(1), 68-104.

Zhang, L. (2006), Estimating Covariation: Epps Effect and Microstructure Noise, Working paper.

Zhang, L., P. Mykland and Y. Aït-Sahalia (2005), A Tale of Two Time Scales: Determining Integrated Volatility with Noisy High-Frequency Data, Journal of the American Statistical Association 100(472), 1394-1411. 
Table 1: Realized co-range and realized covariance with continuous trading and no market frictions

\begin{tabular}{|c|c|c|c|c|c|c|c|c|}
\hline \multirow{2}{*}{$\begin{array}{l}\text { Frequency } \\
\text { (minutes) }\end{array}$} & \multicolumn{2}{|c|}{$R R C O V_{t}^{\Delta}$} & \multicolumn{2}{|c|}{$R R C O V_{S, t}^{\Delta}$} & \multicolumn{2}{|c|}{$R V C O V_{t}^{\Delta}$} & \multicolumn{2}{|c|}{$R V C O V_{S, t}^{\Delta}$} \\
\hline & Mean & RMSE & Mean & RMSE & Mean & RMSE & Mean & RMSE \\
\hline 1 & 3.928 & 0.130 & 3.945 & 0.505 & 3.999 & 0.229 & 4.000 & 1.045 \\
\hline 2 & 3.946 & 0.160 & 3.944 & 0.513 & 3.996 & 0.322 & 3.999 & 1.067 \\
\hline 3 & 3.955 & 0.190 & 3.944 & 0.526 & 3.990 & 0.402 & 4.000 & 1.112 \\
\hline 4 & 3.961 & 0.218 & 3.944 & 0.539 & 3.988 & 0.469 & 3.999 & 1.125 \\
\hline 5 & 3.963 & 0.236 & 3.945 & 0.545 & 3.995 & 0.513 & 4.002 & 1.147 \\
\hline 10 & 3.965 & 0.335 & 3.944 & 0.591 & 3.963 & 0.733 & 3.996 & 1.259 \\
\hline 15 & 3.957 & 0.422 & 3.943 & 0.647 & 3.961 & 0.931 & 4.000 & 1.404 \\
\hline 20 & 3.959 & 0.469 & 3.943 & 0.684 & 3.958 & 1.008 & 3.999 & 1.440 \\
\hline 30 & 3.961 & 0.595 & 3.942 & 0.769 & 3.968 & 1.302 & 4.000 & 1.645 \\
\hline 45 & 3.953 & 0.724 & 3.940 & 0.868 & 3.976 & 1.607 & 3.995 & 1.903 \\
\hline 60 & 3.951 & 0.846 & 3.937 & 0.969 & 3.994 & 1.850 & 3.986 & 2.092 \\
\hline 90 & 3.990 & 1.064 & 3.942 & 1.157 & 4.033 & 2.317 & 4.000 & 2.498 \\
\hline 120 & 3.956 & 1.191 & 3.931 & 1.273 & 3.944 & 2.553 & 3.985 & 2.701 \\
\hline 180 & 3.946 & 1.524 & 3.940 & 1.592 & 3.947 & 3.268 & 4.009 & 3.407 \\
\hline 240 & 3.951 & 1.757 & 3.942 & 1.808 & 4.040 & 3.688 & 4.002 & 3.781 \\
\hline 360 & 3.945 & 2.029 & 3.929 & 2.065 & 3.816 & 4.180 & 3.977 & 4.216 \\
\hline 720 & 3.919 & 2.930 & 3.941 & 2.951 & 3.710 & 6.085 & 4.005 & 6.105 \\
\hline 1440 & 3.928 & 4.044 & 3.928 & 4.044 & 3.985 & 8.830 & 3.985 & 8.830 \\
\hline
\end{tabular}

Note: The table summarizes the results of a simulation experiment where 5000 days of $8,640,000(\log )$ prices (100 prices per second) are simulated from a bivariate normal distribution with mean zero, variance 4 and 16 and correlation 0.5 , such that the true covariance is equal to 4 . All prices are observed. For each day the realized co-range $\left(R R C O V_{t}^{\Delta}\right)$, the bias-corrected realized co-range $\left(R R C O V_{S, t}^{\Delta}\right)$, the realized covariance $\left(R V C O V_{t}^{\Delta}\right)$, and the bias-corrected realized covariance $\left(R V C O V_{S, t}^{\Delta}\right)$ are computed for various sampling frequencies shown in column 1. RRCOV $\Delta$, and $R V C O V_{S, t}^{\Delta}$ are obtained from (9) and (8) with $Q=66$ (with $R R$ and $R V$ replaced by $R R C O V$ and $R V C O V$ ). 
Table 2: Realized co-range and realized covariance with infrequent trading

\begin{tabular}{|c|c|c|c|c|c|c|c|c|}
\hline \multirow{2}{*}{$\begin{array}{l}\text { Frequency } \\
\text { (minutes) }\end{array}$} & \multicolumn{2}{|c|}{$R R C O V_{t}^{\Delta}$} & \multicolumn{2}{|c|}{$R R C O V_{S, t}^{\Delta}$} & \multicolumn{2}{|c|}{$R V C O V_{t}^{\Delta}$} & \multicolumn{2}{|c|}{$R V C O V_{S, t}^{\Delta}$} \\
\hline & Mean & RMSE & Mean & RMSE & Mean & RMSE & Mean & RMSE \\
\hline 1 & 2.017 & 1.985 & 3.866 & 0.547 & 3.203 & 0.828 & 3.979 & 1.210 \\
\hline 2 & 2.470 & 1.535 & 3.866 & 0.557 & 3.596 & 0.521 & 3.980 & 1.235 \\
\hline 3 & 2.696 & 1.314 & 3.866 & 0.564 & 3.731 & 0.482 & 3.979 & 1.254 \\
\hline 4 & 2.836 & 1.179 & 3.866 & 0.572 & 3.791 & 0.506 & 3.979 & 1.277 \\
\hline 5 & 2.937 & 1.084 & 3.866 & 0.583 & 3.833 & 0.550 & 3.980 & 1.300 \\
\hline 10 & 3.211 & 0.849 & 3.866 & 0.626 & 3.914 & 0.751 & 3.979 & 1.399 \\
\hline 15 & 3.339 & 0.770 & 3.865 & 0.667 & 3.942 & 0.927 & 3.979 & 1.493 \\
\hline 20 & 3.418 & 0.739 & 3.866 & 0.703 & 3.955 & 1.045 & 3.979 & 1.574 \\
\hline 30 & 3.516 & 0.748 & 3.866 & 0.780 & 3.961 & 1.294 & 3.977 & 1.743 \\
\hline 45 & 3.592 & 0.813 & 3.866 & 0.877 & 3.960 & 1.590 & 3.978 & 1.967 \\
\hline 60 & 3.641 & 0.893 & 3.864 & 0.973 & 3.959 & 1.818 & 3.979 & 2.158 \\
\hline 90 & 3.694 & 1.043 & 3.865 & 1.123 & 3.936 & 2.175 & 3.981 & 2.469 \\
\hline 120 & 3.737 & 1.193 & 3.867 & 1.270 & 3.951 & 2.575 & 3.983 & 2.809 \\
\hline 180 & 3.770 & 1.428 & 3.866 & 1.495 & 3.903 & 3.089 & 3.979 & 3.297 \\
\hline 240 & 3.799 & 1.651 & 3.866 & 1.708 & 3.951 & 3.595 & 3.983 & 3.768 \\
\hline 360 & 3.795 & 2.008 & 3.868 & 2.044 & 3.917 & 4.427 & 3.986 & 4.562 \\
\hline 720 & 3.821 & 2.856 & 3.863 & 2.874 & 3.898 & 6.163 & 3.977 & 6.234 \\
\hline 1440 & 3.862 & 4.173 & 3.862 & 4.173 & 3.976 & 9.192 & 3.976 & 9.192 \\
\hline
\end{tabular}

Note: The table summarizes the results of a simulation experiment where 5000 days of $8,640,000(\log )$ prices (100 prices per second) are simulated from a bivariate normal distribution with mean zero, variance 4 and 16 and correlation 0.5 , such that the true covariance is equal to 4 . Subsequently, with probability $p_{\text {obs }}=1 /(100 \tau)$ we observe a price and with probability $1-p_{\text {obs }}$ we do not, such that the price is observed on average only every $\tau$ seconds. The table reports results for $\tau=12$. Price observations are drawn independently for both assets. For each day the realized co-range $\left(R R C O V_{t}^{\Delta}\right)$, the bias-corrected realized co-range $\left(R R C O V_{S, t}^{\Delta}\right)$, the realized covariance $\left(R V C O V_{t}^{\Delta}\right)$, and the bias-corrected realized covariance $\left(R V C O V_{S, t}^{\Delta}\right)$ are computed for various sampling frequencies shown in column 1. $R R C O V_{S, t}^{\Delta}$ and $R V C O V_{S, t}^{\Delta}$ are obtained from (9) and (8) with $Q=66$ (with $R R$ and $R V$ replaced by $R R C O V$ and $R V C O V$ ). 
Table 3: Realized co-range and realized covariance with bid-ask bounce

\begin{tabular}{|c|c|c|c|c|c|c|c|c|}
\hline \multirow{2}{*}{$\begin{array}{l}\text { Frequency } \\
\text { (minutes) }\end{array}$} & \multicolumn{2}{|c|}{$R R C O V_{t}^{\Delta}$} & \multicolumn{2}{|c|}{$R R C O V_{S, t}^{\Delta}$} & \multicolumn{2}{|c|}{$R V C O V_{t}^{\Delta}$} & \multicolumn{2}{|c|}{$R V C O V_{S, t}^{\Delta}$} \\
\hline & Mean & RMSE & Mean & RMSE & Mean & RMSE & Mean & RMSE \\
\hline 1 & 14.615 & 10.617 & 4.154 & 0.576 & 3.992 & 0.359 & 4.017 & 1.134 \\
\hline 2 & 10.881 & 6.886 & 4.153 & 0.580 & 3.996 & 0.428 & 4.015 & 1.155 \\
\hline 3 & 9.395 & 5.402 & 4.153 & 0.594 & 3.986 & 0.472 & 4.019 & 1.179 \\
\hline 4 & 8.556 & 4.565 & 4.153 & 0.610 & 3.988 & 0.542 & 4.013 & 1.204 \\
\hline 5 & 8.000 & 4.012 & 4.153 & 0.617 & 3.983 & 0.583 & 4.018 & 1.222 \\
\hline 10 & 6.694 & 2.725 & 4.153 & 0.668 & 3.955 & 0.778 & 4.011 & 1.326 \\
\hline 15 & 6.141 & 2.198 & 4.152 & 0.730 & 3.962 & 0.964 & 4.019 & 1.448 \\
\hline 20 & 5.828 & 1.907 & 4.152 & 0.769 & 3.942 & 1.037 & 4.015 & 1.489 \\
\hline 30 & 5.463 & 1.611 & 4.151 & 0.857 & 3.967 & 1.329 & 4.016 & 1.679 \\
\hline 45 & 5.165 & 1.413 & 4.149 & 0.953 & 3.975 & 1.640 & 4.008 & 1.950 \\
\hline 60 & 4.993 & 1.356 & 4.145 & 1.057 & 4.004 & 1.858 & 4.003 & 2.118 \\
\hline 90 & 4.835 & 1.419 & 4.148 & 1.247 & 4.033 & 2.345 & 4.015 & 2.542 \\
\hline 120 & 4.687 & 1.444 & 4.140 & 1.359 & 3.961 & 2.567 & 4.004 & 2.729 \\
\hline 180 & 4.543 & 1.696 & 4.154 & 1.683 & 3.948 & 3.294 & 4.030 & 3.445 \\
\hline 240 & 4.464 & 1.900 & 4.155 & 1.900 & 4.056 & 3.701 & 4.025 & 3.805 \\
\hline 360 & 4.369 & 2.142 & 4.142 & 2.153 & 3.830 & 4.205 & 3.999 & 4.250 \\
\hline 720 & 4.210 & 3.024 & 4.150 & 3.043 & 3.701 & 6.122 & 4.007 & 6.145 \\
\hline 1440 & 4.135 & 4.128 & 4.135 & 4.128 & 3.982 & 8.871 & 3.982 & 8.871 \\
\hline
\end{tabular}

Note: The table summarizes the results of a simulation experiment where 5000 days of $8,640,000(\log )$ prices (100 prices per second) are simulated from a bivariate normal distribution with mean zero, variance 4 and 16 and correlation 0.5 , such that the true covariance is equal to 4. All prices are observed, but are converted to bid and ask prices (with equal probability) by either subtracting or adding half the spread $s=0.0005$ (on a starting price of 1). The occurrence of bid and ask prices for the two assets is independent. For each day the realized co-range $\left(R R C O V_{t}^{\Delta}\right)$, the bias-corrected realized co-range $\left(R R C O V_{S, t}^{\Delta}\right)$, the realized covariance $\left(R V C O V_{t}^{\Delta}\right)$, and the bias-corrected realized covariance $\left(R V C O V_{S, t}^{\Delta}\right)$ are computed for various sampling frequencies shown in column 1. RRCOV $\Delta, t$ and $R V C O V_{S, t}^{\Delta}$ are obtained from (9) and (8) with $Q=66$ (with $R R$ and $R V$ replaced by $R R C O V$ and $R V C O V)$. 
Table 4: Realized co-range and realized covariance with infrequent trading and bid-ask bounce

\begin{tabular}{|c|c|c|c|c|c|c|c|c|}
\hline \multirow{2}{*}{$\begin{array}{l}\text { Frequency } \\
\text { (minutes) }\end{array}$} & \multicolumn{2}{|c|}{$R R C O V_{t}^{\Delta}$} & \multicolumn{2}{|c|}{$R R C O V_{S, t}^{\Delta}$} & \multicolumn{2}{|c|}{$R V C O V_{t}^{\Delta}$} & \multicolumn{2}{|c|}{$R V C O V_{S, t}^{\Delta}$} \\
\hline & Mean & RMSE & Mean & RMSE & Mean & RMSE & Mean & RMSE \\
\hline 1 & 3.861 & 0.210 & 3.956 & 0.555 & 3.213 & 0.869 & 3.973 & 1.237 \\
\hline 2 & 4.082 & 0.205 & 3.956 & 0.565 & 3.599 & 0.583 & 3.973 & 1.257 \\
\hline 3 & 4.129 & 0.250 & 3.956 & 0.574 & 3.732 & 0.551 & 3.972 & 1.280 \\
\hline 4 & 4.142 & 0.278 & 3.956 & 0.584 & 3.793 & 0.574 & 3.972 & 1.301 \\
\hline 5 & 4.143 & 0.301 & 3.957 & 0.596 & 3.836 & 0.608 & 3.973 & 1.322 \\
\hline 10 & 4.139 & 0.387 & 3.956 & 0.645 & 3.917 & 0.794 & 3.971 & 1.425 \\
\hline 15 & 4.126 & 0.460 & 3.956 & 0.689 & 3.944 & 0.956 & 3.972 & 1.512 \\
\hline 20 & 4.114 & 0.514 & 3.956 & 0.727 & 3.962 & 1.078 & 3.971 & 1.598 \\
\hline 30 & 4.100 & 0.625 & 3.956 & 0.809 & 3.963 & 1.312 & 3.970 & 1.757 \\
\hline 45 & 4.079 & 0.752 & 3.956 & 0.908 & 3.955 & 1.603 & 3.971 & 1.978 \\
\hline 60 & 4.069 & 0.864 & 3.955 & 1.007 & 3.954 & 1.829 & 3.971 & 2.169 \\
\hline 90 & 4.047 & 1.039 & 3.956 & 1.155 & 3.933 & 2.188 & 3.974 & 2.478 \\
\hline 120 & 4.045 & 1.209 & 3.957 & 1.307 & 3.952 & 2.587 & 3.975 & 2.822 \\
\hline 180 & 4.024 & 1.452 & 3.956 & 1.532 & 3.900 & 3.098 & 3.972 & 3.305 \\
\hline 240 & 4.020 & 1.678 & 3.956 & 1.744 & 3.950 & 3.601 & 3.974 & 3.775 \\
\hline 360 & 3.976 & 2.040 & 3.958 & 2.083 & 3.917 & 4.444 & 3.979 & 4.578 \\
\hline 720 & 3.949 & 2.893 & 3.954 & 2.913 & 3.899 & 6.165 & 3.969 & 6.236 \\
\hline 1440 & 3.952 & 4.208 & 3.952 & 4.208 & 3.968 & 9.183 & 3.968 & 9.183 \\
\hline
\end{tabular}

Note: The table summarizes the results of a simulation experiment where 5000 days of 8,640,000 (log) prices (100 prices per second) are simulated from a bivariate normal distribution with mean zero, variance 4 and 16 and correlation 0.5 , such that the true covariance is equal to 4 . Subsequently with probability $p_{\text {obs }}=1 /(100 \tau)$ we observe a price and with probability $1-p_{\text {obs }}$ we do not, such that the price is observed on average only every $\tau$ seconds. The table reports results for $\tau=12$. The observed prices are converted to bid and ask prices (with equal probability) by either subtracting or adding half the spread $s=0.0005$ (on a starting price of 1). The occurrence of price observations and bid and ask prices for the two assets is independent. For each day the realized co-range $\left(R R C O V_{t}^{\Delta}\right)$, the bias-corrected realized co-range $\left(R R C O V_{S, t}^{\Delta}\right)$, the realized covariance $\left(R V C O V_{t}^{\Delta}\right)$, and the bias-corrected realized covariance $\left(R V C O V_{S, t}\right)$ are computed for various sampling frequencies shown in column 1. $R R C O V_{S, t}^{\Delta}$ and $R V C O V_{S, t}^{\Delta}$ are obtained from (9) and (8) with $Q=66$ (with $R R$ and $R V$ replaced by $R R C O V$ and $R V C O V$ ). 
Table 5: Realized co-range and realized covariance with infrequent trading and bidask bounce

\begin{tabular}{|c|c|c|c|c|c|c|c|c|c|c|c|c|}
\hline \multirow{2}{*}{$\begin{array}{l}\text { Trading } \\
\text { frequency } \\
\text { (seconds) }\end{array}$} & \multicolumn{3}{|c|}{$s=0$} & \multicolumn{3}{|c|}{$s=0.00025$} & \multicolumn{3}{|c|}{$s=0.0005$} & \multicolumn{3}{|c|}{$s=0.00075$} \\
\hline & $\mathrm{SF}$ & Mean & RMSE & $\mathrm{SF}$ & Mean & RMSE & SF & Mean & RMSE & $\mathrm{SF}$ & Meean & RMSE \\
\hline \multicolumn{13}{|l|}{$R R C O V_{t}^{\Delta}$} \\
\hline 2 & 10 & 3.652 & 0.480 & 8 & 4.276 & 0.420 & 36 & 4.753 & 1.029 & 72 & 5.016 & 1.425 \\
\hline 3 & 12 & 3.613 & 0.531 & 1 & 4.133 & 0.179 & 36 & 4.626 & 0.934 & 72 & 4.916 & 1.351 \\
\hline 4 & 15 & 3.600 & 0.571 & 2 & 3.879 & 0.199 & 36 & 4.524 & 0.866 & 72 & 4.834 & 1.291 \\
\hline 6 & 20 & 3.576 & 0.629 & 6 & 3.728 & 0.379 & 18 & 4.524 & 0.721 & 72 & 4.700 & 1.202 \\
\hline 10 & 20 & 3.464 & 0.705 & 12 & 3.592 & 0.549 & 5 & 4.349 & 0.440 & 36 & 4.730 & 1.016 \\
\hline 12 & 24 & 3.458 & 0.738 & 15 & 3.557 & 0.604 & 2 & 4.082 & 0.205 & 36 & 4.621 & 0.937 \\
\hline 15 & 24 & 3.401 & 0.779 & 16 & 3.472 & 0.674 & 4 & 3.865 & 0.272 & 24 & 4.592 & 0.828 \\
\hline 20 & 30 & 3.387 & 0.830 & 24 & 3.456 & 0.743 & 10 & 3.720 & 0.447 & 1 & 4.109 & 0.238 \\
\hline 30 & 40 & 3.358 & 0.906 & 32 & 3.383 & 0.847 & 20 & 3.564 & 0.643 & 4 & 3.872 & 0.292 \\
\hline 40 & 40 & 3.271 & 0.965 & 40 & 3.345 & 0.917 & 24 & 3.429 & 0.765 & 10 & 3.686 & 0.483 \\
\hline 50 & 48 & 3.253 & 1.019 & 40 & 3.263 & 0.975 & 32 & 3.387 & 0.851 & 15 & 3.546 & 0.625 \\
\hline 60 & 48 & 3.192 & 1.061 & 45 & 3.222 & 1.026 & 40 & 3.355 & 0.917 & 20 & 3.456 & 0.727 \\
\hline \multicolumn{13}{|l|}{$R R C O V_{S, t}^{\Delta}$} \\
\hline 2 & 1 & 3.908 & 0.542 & 1 & 3.961 & 0.545 & 1 & 4.059 & 0.571 & 2 & 4.164 & 0.630 \\
\hline 3 & 1 & 3.902 & 0.542 & 1 & 3.948 & 0.544 & 1 & 4.041 & 0.566 & 2 & 4.144 & 0.623 \\
\hline 4 & 1 & 3.897 & 0.543 & 1 & 3.938 & 0.542 & 1 & 4.026 & 0.562 & 2 & 4.128 & 0.617 \\
\hline 6 & 1 & 3.887 & 0.544 & 1 & 3.921 & 0.543 & 1 & 4.002 & 0.559 & 2 & 4.100 & 0.607 \\
\hline 10 & 1 & 3.871 & 0.546 & 1 & 3.899 & 0.545 & 1 & 3.968 & 0.552 & 1 & 4.059 & 0.589 \\
\hline 12 & 1 & 3.866 & 0.547 & 1 & 3.891 & 0.547 & 1 & 3.956 & 0.555 & 1 & 4.045 & 0.589 \\
\hline 15 & 1 & 3.857 & 0.548 & 1 & 3.881 & 0.548 & 1 & 3.942 & 0.553 & 1 & 4.026 & 0.582 \\
\hline 20 & 1 & 3.843 & 0.550 & 1 & 3.864 & 0.548 & 1 & 3.921 & 0.549 & 1 & 4.001 & 0.570 \\
\hline 30 & 1 & 3.824 & 0.556 & 1 & 3.842 & 0.551 & 2 & 3.890 & 0.558 & 1 & 3.960 & 0.556 \\
\hline 40 & 1 & 3.808 & 0.559 & 1 & 3.820 & 0.555 & 1 & 3.861 & 0.550 & 1 & 3.923 & 0.553 \\
\hline 50 & 1 & 3.791 & 0.563 & 1 & 3.804 & 0.557 & 1 & 3.841 & 0.550 & 1 & 3.898 & 0.550 \\
\hline 60 & 1 & 3.776 & 0.565 & 1 & 3.787 & 0.561 & 1 & 3.821 & 0.555 & 1 & 3.874 & 0.552 \\
\hline \multicolumn{13}{|l|}{$R V C O V_{t}^{\Delta}$} \\
\hline 2 & 1 & 3.866 & 0.268 & 1 & 3.867 & 0.296 & 1 & 3.868 & 0.393 & 2 & 3.942 & 0.556 \\
\hline 3 & 1 & 3.799 & 0.306 & 1 & 3.798 & 0.331 & 1 & 3.798 & 0.418 & 2 & 3.903 & 0.560 \\
\hline 4 & 1 & 3.733 & 0.353 & 1 & 3.732 & 0.374 & 2 & 3.866 & 0.449 & 2 & 3.869 & 0.568 \\
\hline 6 & 2 & 3.797 & 0.388 & 2 & 3.798 & 0.411 & 2 & 3.798 & 0.476 & 2 & 3.798 & 0.590 \\
\hline 10 & 3 & 3.776 & 0.457 & 3 & 3.774 & 0.477 & 3 & 3.772 & 0.532 & 3 & 0.583 & 0.626 \\
\hline 12 & 3 & 3.731 & 0.482 & 3 & 3.732 & 0.499 & 3 & 3.732 & 0.551 & 3 & 3.733 & 0.642 \\
\hline 15 & 3 & 3.666 & 0.521 & 3 & 3.664 & 0.536 & 3 & 3.663 & 0.585 & 4 & 3.747 & 0.670 \\
\hline 20 & 4 & 3.657 & 0.576 & 4 & 3.656 & 0.589 & 4 & 3.657 & 0.631 & 4 & 3.657 & 0.704 \\
\hline 30 & 6 & 3.661 & 0.657 & 6 & 3.662 & 0.666 & 6 & 3.663 & 0.701 & 6 & 3.665 & 0.762 \\
\hline 40 & 6 & 3.548 & 0.720 & 6 & 3.550 & 0.728 & 6 & 3.553 & 0.759 & 6 & 3.556 & 0.815 \\
\hline 50 & 8 & 3.578 & 0.787 & 8 & 3.581 & 0.796 & 8 & 3.585 & 0.826 & 8 & 3.588 & 0.877 \\
\hline 60 & 8 & 3.491 & 0.835 & 8 & 3.495 & 0.843 & 8 & 3.499 & 0.870 & 8 & 3.503 & 0.918 \\
\hline \multicolumn{13}{|c|}{$R V C O V_{S, t}^{\Delta}$} \\
\hline 2 & 1 & 3.981 & 1.208 & 1 & 3.978 & 1.212 & 1 & 3.976 & 1.237 & 1 & 3.974 & 1.301 \\
\hline 3 & 1 & 3.981 & 1.208 & 1 & 3.979 & 1.212 & 1 & 3.978 & 1.236 & 1 & 3.976 & 1.298 \\
\hline 4 & 1 & 3.982 & 1.208 & 1 & 3.980 & 1.212 & 1 & 3.979 & 1.235 & 1 & 3.978 & 1.296 \\
\hline 6 & 1 & 3.981 & 1.209 & 1 & 3.978 & 1.213 & 1 & 3.976 & 1.239 & 1 & 3.973 & 1.305 \\
\hline 10 & 1 & 3.980 & 1.209 & 1 & 3.976 & 1.210 & 1 & 3.972 & 1.232 & 1 & 3.968 & 1.292 \\
\hline 12 & 1 & 3.979 & 1.210 & 1 & 3.976 & 1.212 & 1 & 3.973 & 1.237 & 2 & 3.970 & 1.301 \\
\hline 15 & 1 & 3.979 & 1.211 & 1 & 3.976 & 1.216 & 1 & 3.974 & 1.241 & 1 & 3.973 & 1.305 \\
\hline 20 & 1 & 3.977 & 1.208 & 1 & 3.975 & 1.213 & 1 & 3.973 & 1.239 & 1 & 3.972 & 1.300 \\
\hline 30 & 1 & 3.975 & 1.206 & 1 & 3.972 & 1.211 & 1 & 3.969 & 1.234 & 1 & 3.966 & 1.288 \\
\hline 40 & 1 & 3.977 & 1.213 & 1 & 3.975 & 1.218 & 1 & 3.974 & 1.238 & 1 & 3.972 & 1.283 \\
\hline 50 & 1 & 3.976 & 1.216 & 1 & 3.974 & 1.221 & 1 & 3.973 & 1.239 & 1 & 3.971 & 1.277 \\
\hline 60 & 1 & 3.974 & 1.217 & 1 & 3.972 & 1.222 & 1 & 3.970 & 1.238 & 1 & 3.969 & 1.272 \\
\hline
\end{tabular}

Note: The table provides results for the simulation experiment with infrequent and nonsynchronous trading and bid-ask bounce for different trading frequencies $\tau$, ranging from 2 to 60 seconds, and different bid-ask spreads $s$, ranging from 0 to 0.00075 . See Table 4 for details of the simulation set-up. For each combination of $\tau$ and $s$, the table shows the optimal sampling frequency for the four covariance estimators, along with the corresponding RMSE and mean. The covariance estimator that achieves the lowest RMSE for a given combination of $\tau$ and $s$ is shown in italics. 
Table 6: Summary statistics

\begin{tabular}{|c|c|c|c|c|c|c|}
\hline & Stocks & Bonds & Gold & & & \\
\hline Mean & 0.072 & 0.044 & -0.011 & & & \\
\hline St.Dev. & 0.166 & 0.104 & 0.150 & & & \\
\hline Skewness & -0.720 & 0.464 & -0.229 & & & \\
\hline Kurtosis & 17.417 & 16.290 & 10.182 & & & \\
\hline Correlations & Stocks & Bonds & Gold & & & \\
\hline Stocks & 1 & & & & & \\
\hline Bonds & 0.101 & 1 & & & & \\
\hline Gold & -0.107 & -0.070 & 1 & & & \\
\hline & $\begin{array}{l}\sqrt{R V_{s}} \\
0104\end{array}$ & $\begin{array}{l}\sqrt{\sqrt{R R_{s}}} \\
0069\end{array}$ & $\begin{array}{l}\sqrt{R V_{b}} \\
0078\end{array}$ & $\sqrt{\overline{R R_{b}}}$ & $\begin{array}{l}\sqrt{R V_{g}} \\
0109\end{array}$ & $\begin{array}{l}\sqrt{R R_{g}} \\
0.07 ?\end{array}$ \\
\hline $\begin{array}{l}\text { Mean } \\
\text { St.Dev. }\end{array}$ & $\begin{array}{l}0.104 \\
0.053\end{array}$ & $\begin{array}{l}0.009 \\
0.032\end{array}$ & $\begin{array}{l}0.078 \\
0.032\end{array}$ & $\begin{array}{l}0.053 \\
0.018\end{array}$ & 0.055 & 0.033 \\
\hline Skewness & 2.658 & 2.519 & 1.912 & 1.784 & 2.207 & 2.059 \\
\hline Kurtosis & 16.818 & 15.161 & 9.667 & 9.692 & 13.059 & 12.168 \\
\hline & $R V$ corr $_{s, b}$ & RRcorr $_{s, b}$ & $R V$ corr $_{g, s}$ & RRcorr $_{g, s}$ & $R$ Corr $_{g, b}$ & RRcorr $_{g, b}$ \\
\hline Mean & 0.112 & 0.128 & -0.056 & 0.003 & 0.006 & 0.070 \\
\hline St.Dev. & 0.388 & 0.314 & 0.179 & 0.128 & 0.183 & 0.122 \\
\hline Skewness & -0.501 & -0.593 & -0.445 & -0.513 & 0.136 & 0.033 \\
\hline Kurtosis & 2.229 & 2.568 & 3.555 & 3.878 & 3.461 & 3.597 \\
\hline
\end{tabular}

Note: This table summarizes the data statistics of the daily returns, realized volatility and realized range estimators and the correlations implied by the intraday estimators for the stocks (s), bond (b), and gold (g) futures. $\sqrt{R V_{x}}$ represents the annualized realized volatility sampled at the 5 -minute frequency and $\sqrt{R R_{x}}$ is the realized range. The realized correlations implied by the realized covariance $(5 \mathrm{~min})$ are denoted $R V$ corr $_{x, y}$ and $R V \operatorname{corr}_{x, y}$ is the correlation implied by the realized co-range. 
Table 7: Volatility timing strategy

\begin{tabular}{|c|c|c|c|c|c|c|c|c|c|c|}
\hline & \multicolumn{5}{|c|}{ Realized Co-Range (5 min) } & \multicolumn{5}{|c|}{ Realized Covariance (5 min) } \\
\hline & Mean & St.Dev. & SR & TO & BETC & Mean & St.Dev. & SR & TO & BETC \\
\hline $1985-2006$ & 0.094 & 0.072 & 1.306 & 5.9 & 159.8 & 0.093 & 0.072 & 1.291 & 9.5 & 98.4 \\
\hline 1985 & 0.000 & 0.061 & -0.007 & 2.9 & -1.4 & 0.004 & 0.061 & 0.058 & 4.6 & 7.8 \\
\hline $1986-1988$ & 0.110 & 0.078 & 1.406 & 5.5 & 199.8 & 0.110 & 0.079 & 1.381 & 9.1 & 121.0 \\
\hline 1989-1991 & 0.132 & 0.070 & 1.879 & 6.4 & 207.4 & 0.130 & 0.070 & 1.856 & 9.6 & 135.1 \\
\hline 1992-1994 & 0.092 & 0.053 & 1.746 & 5.7 & 161.4 & 0.087 & 0.053 & 1.642 & 9.2 & 94.3 \\
\hline 1995-1997 & 0.161 & 0.047 & 3.412 & 4.5 & 360.6 & 0.161 & 0.047 & 3.403 & 7.3 & 221.4 \\
\hline $1998-2000$ & 0.132 & 0.073 & 1.822 & 5.7 & 233.2 & 0.130 & 0.073 & 1.787 & 8.8 & 147.8 \\
\hline 2001-2003 & 0.014 & 0.085 & 0.169 & 5.3 & 27.1 & 0.017 & 0.085 & 0.203 & 8.9 & 19.3 \\
\hline \multirow{3}{*}{ 2004-2006 } & 0.038 & 0.084 & 0.446 & 8.3 & 45.5 & 0.036 & 0.084 & 0.432 & 13.6 & 26.8 \\
\hline & \multicolumn{5}{|c|}{ Daily Co-Range } & \multicolumn{5}{|c|}{ Daily Covariance } \\
\hline & Mean & St.Dev. & SR & TO & BETC & Mean & St.Dev. & SR & TO & BETC \\
\hline $1985-2006$ & 0.088 & 0.072 & 1.224 & 17.1 & 51.6 & 0.091 & 0.074 & 1.234 & 10.2 & 89.0 \\
\hline 1985 & -0.006 & 0.060 & -0.092 & 8.3 & -6.7 & -0.001 & 0.064 & -0.020 & 5.0 & -2.6 \\
\hline $1986-1988$ & 0.107 & 0.079 & 1.362 & 14.6 & 73.7 & 0.123 & 0.080 & 1.534 & 8.8 & 139.3 \\
\hline 1989-1991 & 0.120 & 0.069 & 1.742 & 17.2 & 69.5 & 0.119 & 0.070 & 1.695 & 9.8 & 121.4 \\
\hline 1992-1994 & 0.087 & 0.052 & 1.658 & 14.6 & 59.4 & 0.096 & 0.054 & 1.779 & 9.3 & 102.6 \\
\hline 1995-1997 & 0.156 & 0.047 & 3.300 & 13.1 & 118.9 & 0.153 & 0.049 & 3.150 & 8.0 & 190.7 \\
\hline $1998-2000$ & 0.121 & 0.073 & 1.657 & 15.4 & 78.9 & 0.120 & 0.075 & 1.598 & 9.3 & 128.4 \\
\hline 2001-2003 & 0.021 & 0.085 & 0.242 & 20.6 & 10.0 & 0.020 & 0.086 & 0.230 & 11.5 & 17.2 \\
\hline 2004-2006 & 0.028 & 0.085 & 0.333 & 24.5 & 11.6 & 0.026 & 0.086 & 0.303 & 14.7 & 17.7 \\
\hline
\end{tabular}

Note: This table summarizes the performance statistics of the volatility timing strategy based on the bias-corrected rolling estimators constructed from 5 minute return data (realized covariance) and 5 minute range data (realized co-range). The decay parameter $\alpha$ is estimated in a maximum-likelihood procedure. The annualized average daily portfolio return is denoted by Mean and St.Dev. represents the corresponding annualized volatility of daily portfolio returns. TO is the annualized average absolute daily change in portfolio weights. BETC represents the annualized break-even transaction costs (in basis points), which would reduce the profitability of the investment strategy to zero. 
Table 8: Volatility timing strategy: Sensitivity analysis for decay rate

\begin{tabular}{ccccccccccc}
\hline \hline \multicolumn{4}{c}{ Realized Co-Range (5 min) } & \multicolumn{3}{c}{ Realized Covariance (5 min) } \\
$\alpha$ & Mean & St.Dev. & SR & TO & BETC & Mean & St.Dev. & SR & TO & BETC \\
\hline 0.010 & 0.095 & 0.074 & 1.279 & 1.1 & 846.0 & 0.095 & 0.074 & 1.286 & 1.7 & 567.8 \\
0.025 & 0.095 & 0.073 & 1.304 & 2.6 & 369.2 & 0.095 & 0.073 & 1.310 & 4.0 & 236.2 \\
0.050 & 0.094 & 0.072 & 1.308 & 4.8 & 198.1 & 0.094 & 0.072 & 1.302 & 7.8 & 121.3 \\
0.075 & 0.094 & 0.072 & 1.303 & 6.8 & 137.4 & 0.093 & 0.072 & 1.284 & 11.4 & 81.1 \\
0.100 & 0.093 & 0.072 & 1.297 & 8.8 & 105.7 & 0.091 & 0.072 & 1.264 & 15.1 & 60.5 \\
0.125 & 0.093 & 0.072 & 1.292 & 10.8 & 86.3 & 0.090 & 0.072 & 1.243 & 18.9 & 47.7 \\
0.150 & 0.093 & 0.072 & 1.288 & 12.7 & 73.2 & 0.096 & 0.083 & 1.153 & 33.7 & 28.6 \\
0.175 & 0.093 & 0.072 & 1.285 & 14.5 & 63.7 & 0.086 & 0.101 & 0.854 & 37.4 & 23.0 \\
& & & & & & & & & & \\
\hline \hline & & & Daily Co-Range & & & & Daily Covariance & \\
$\alpha$ & Mean & St.Dev. & SR & TO & BETC & Mean & St.Dev. & SR & TO & BETC \\
\hline 0.010 & 0.093 & 0.074 & 1.263 & 2.2 & 431.5 & 0.093 & 0.074 & 1.257 & 3.4 & 273.0 \\
0.025 & 0.092 & 0.073 & 1.271 & 5.4 & 172.1 & 0.091 & 0.073 & 1.245 & 8.5 & 107.0 \\
0.050 & 0.090 & 0.072 & 1.251 & 10.6 & 85.2 & 0.088 & 0.074 & 1.181 & 17.1 & 51.2 \\
0.075 & 0.089 & 0.072 & 1.229 & 15.7 & 56.4 & 0.084 & 0.075 & 1.120 & 25.6 & 32.8 \\
0.100 & 0.087 & 0.072 & 1.211 & 20.8 & 42.1 & 0.081 & 0.076 & 1.064 & 34.2 & 23.7 \\
0.125 & 0.086 & 0.072 & 1.195 & 25.7 & 33.6 & 0.079 & 0.077 & 1.014 & 42.8 & 18.4 \\
0.150 & 0.086 & 0.072 & 1.182 & 30.6 & 28.0 & 0.076 & 0.079 & 0.969 & 51.3 & 14.9 \\
0.175 & 0.085 & 0.073 & 1.170 & 35.4 & 24.0 & 0.074 & 0.080 & 0.929 & 59.8 & 12.4 \\
\hline
\end{tabular}

Note: This table displays the performance statistics of the sensitivity analysis for decay rates in the volatility timing strategy based on the bias-corrected rolling estimators constructed from 5 minute return data (realized covariance) and 5 minute range data (realized co-range). $\alpha$ is the decay parameter. The annualized average daily portfolio return is denoted by Mean and St.Dev. represents the corresponding annualized volatility of daily portfolio returns. TO is the annualized average absolute daily change in portfolio weights. BETC represents the annualized break-even transaction costs (in basis points), which would reduce the profitability of the investment strategy to zero. 


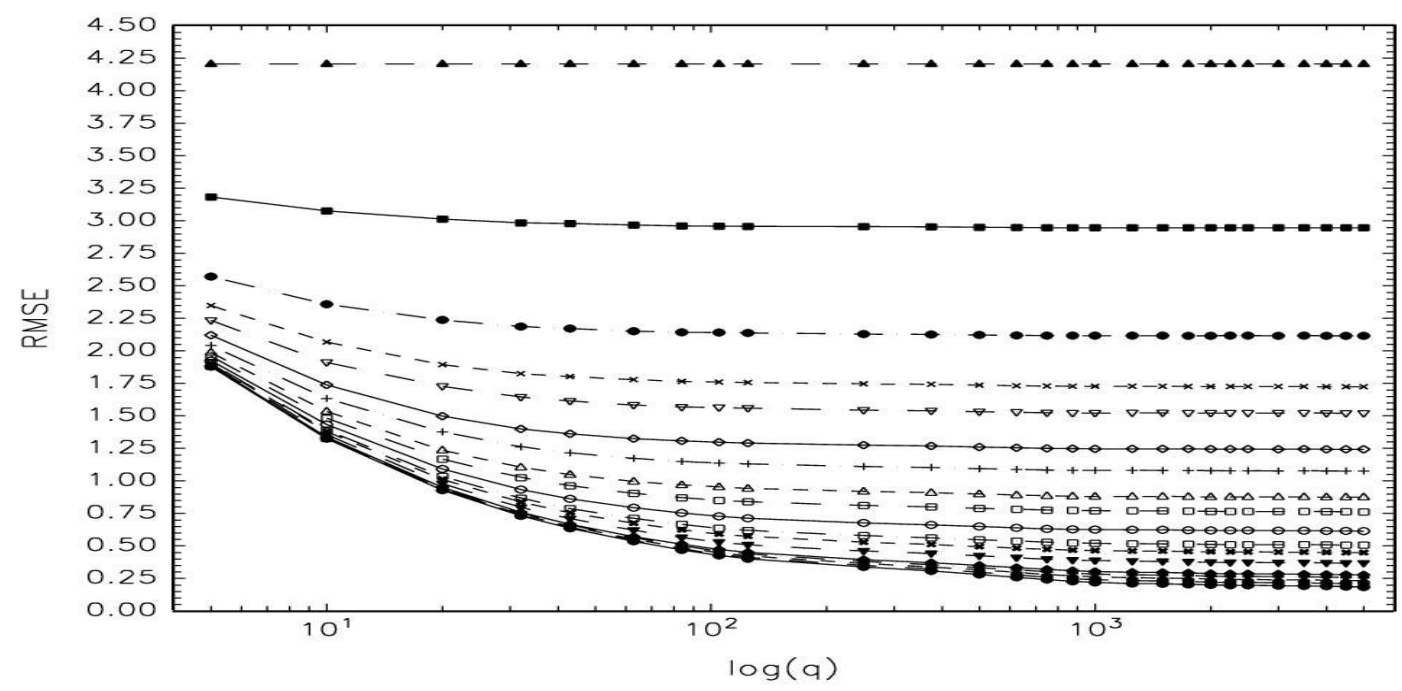

Figure 1: RMSE of the bias-corrected realized co-range $R R C O V_{S, t}^{\Delta}$ obtained from (8) as a function of $Q$, for sampling frequencies as listed in the first column of Table 4. The sampling frequency increases from the top line to the bottom. 


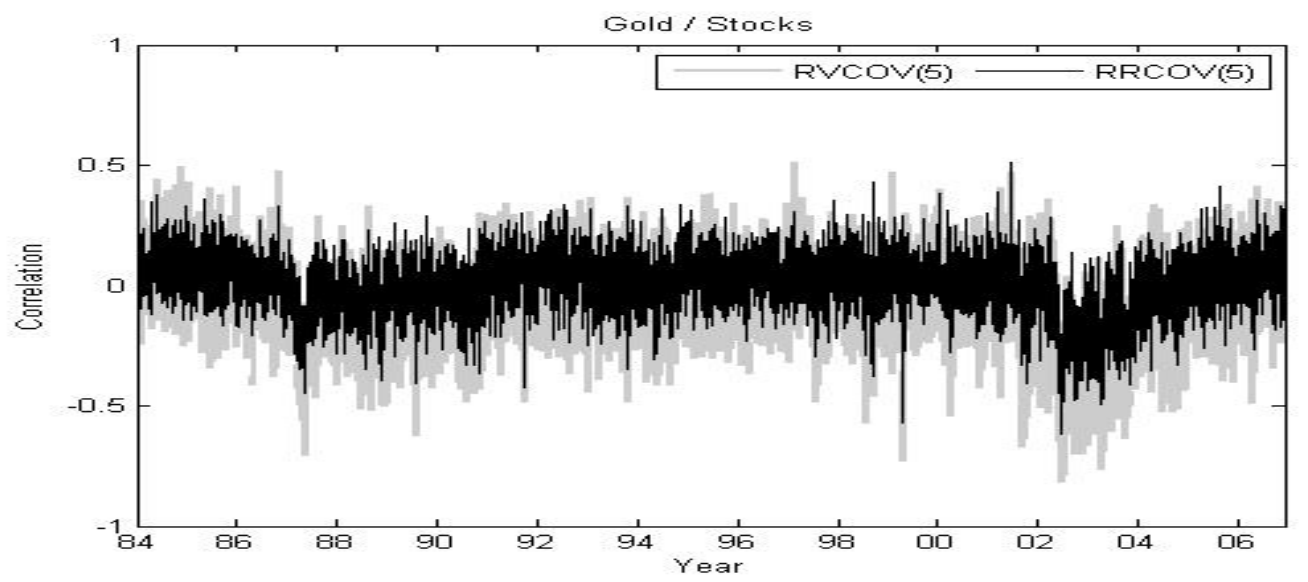

(a) Gold and stocks

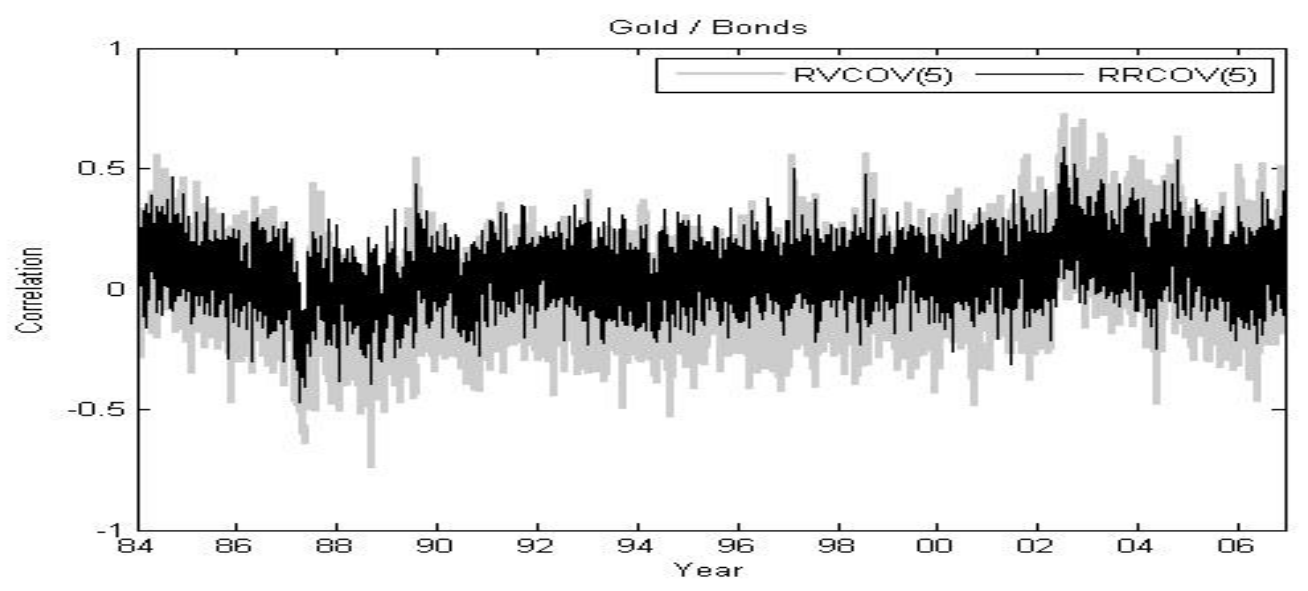

(b) Gold and bonds

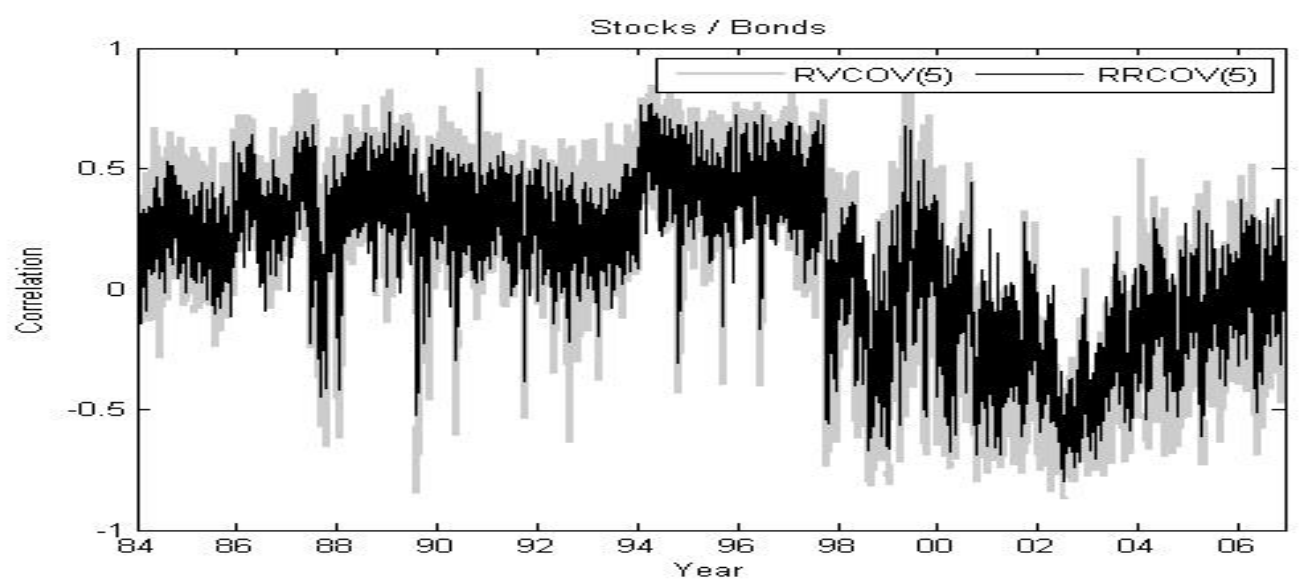

(c) Stocks and bonds

Figure 2: This figure illustrates plots of the realized correlations between gold and stocks (a), gold and bonds (b) and stocks and bonds (c). The correlations are obtained using the 5-minute sampling frequency before bias-corrections and rolling of the covariance estimators. RVCOV(5) is the realized correlation implied by the realized covariance and $\mathrm{RRCOV}(5)$ is the realized correlation implied by the realized co-range. 

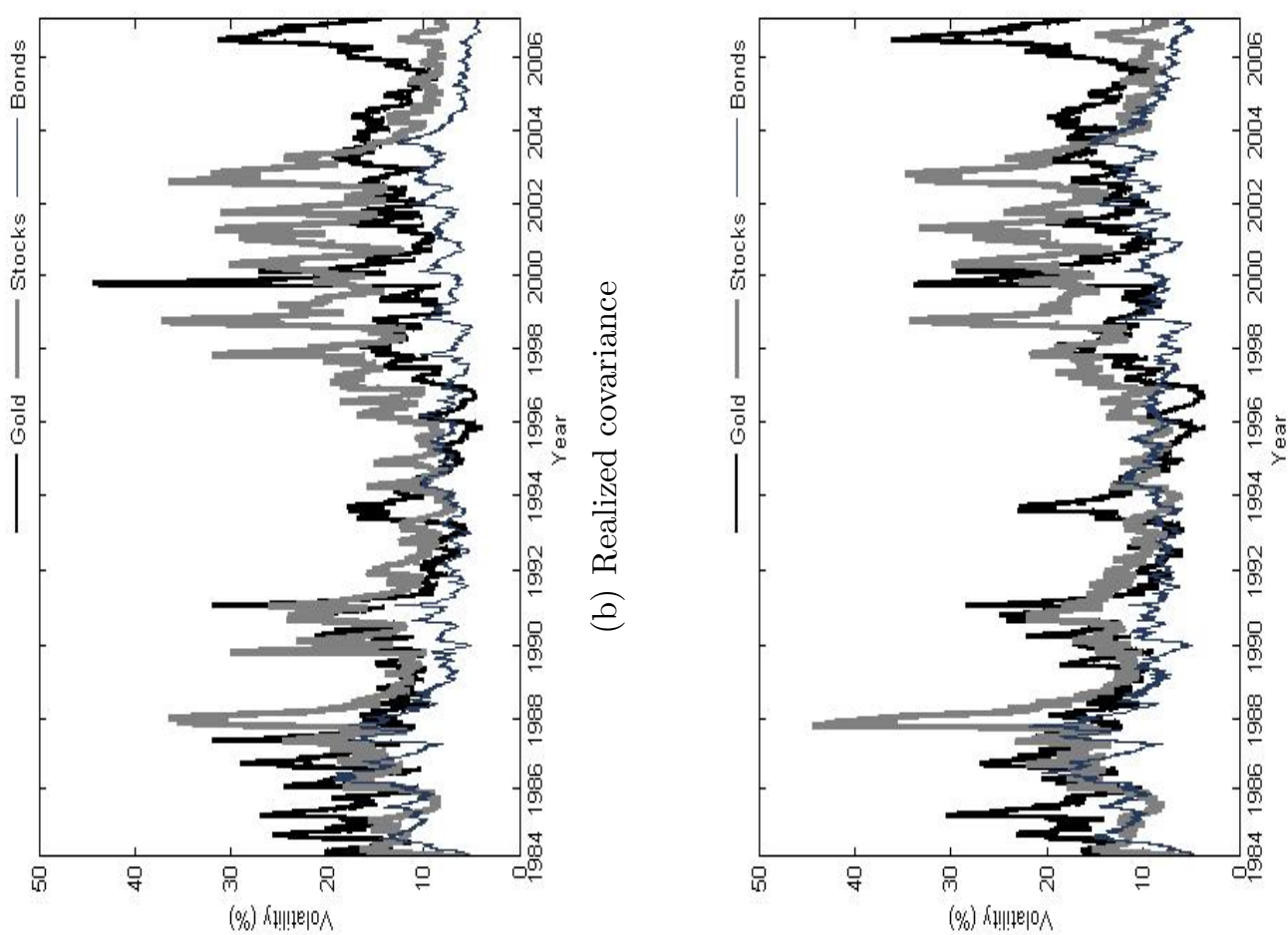

퍼

.

䇆

苛

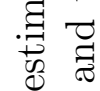

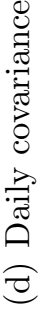

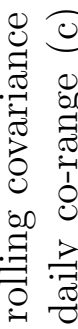

$\stackrel{\frac{9}{2}}{0}$

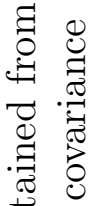

응

㐘
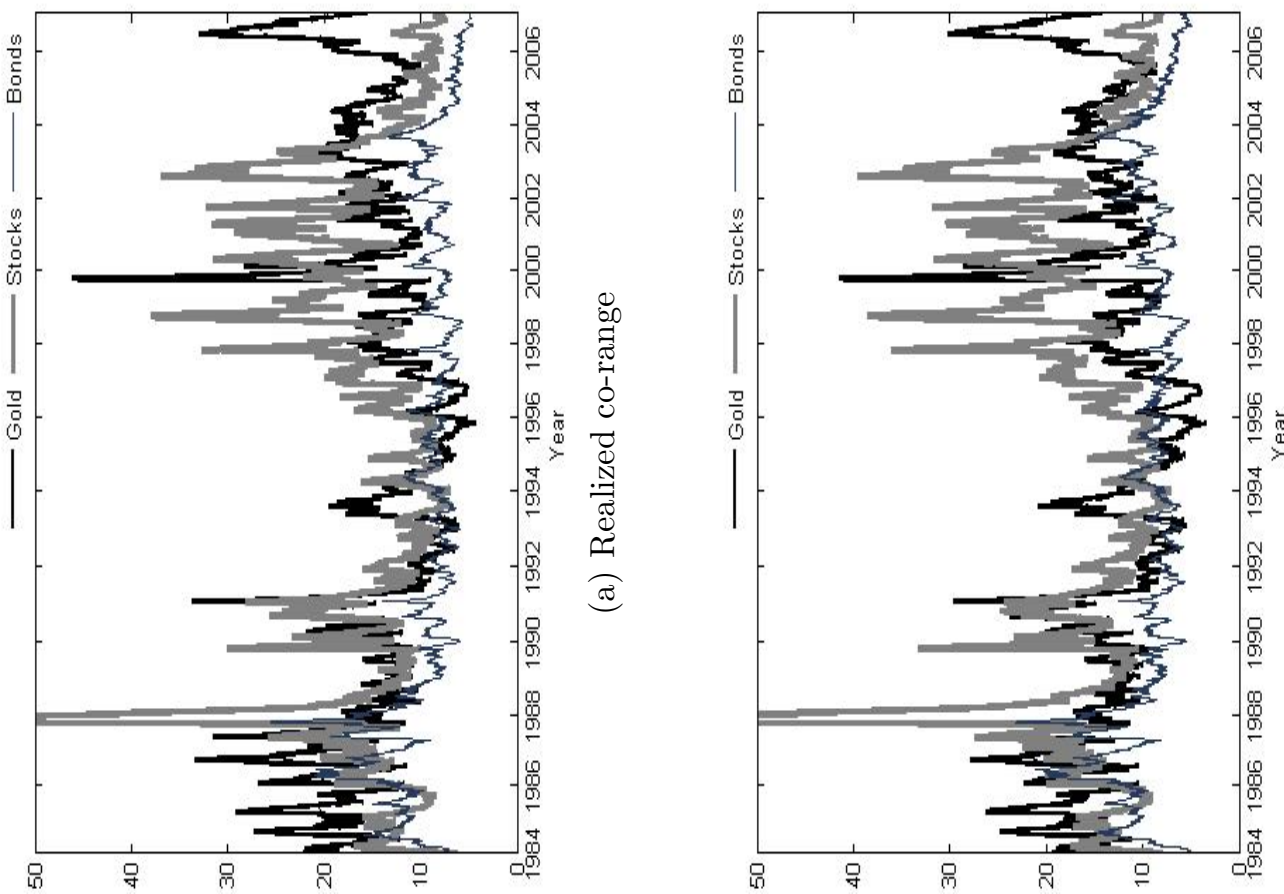

苟

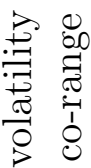

용

范

$\begin{array}{cc}0 \\ 0 \\ 0 & 0 \\ 0 & 0\end{array}$

군

Dै

品

․ㅜ

50

寻 节

的击

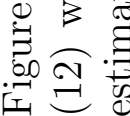




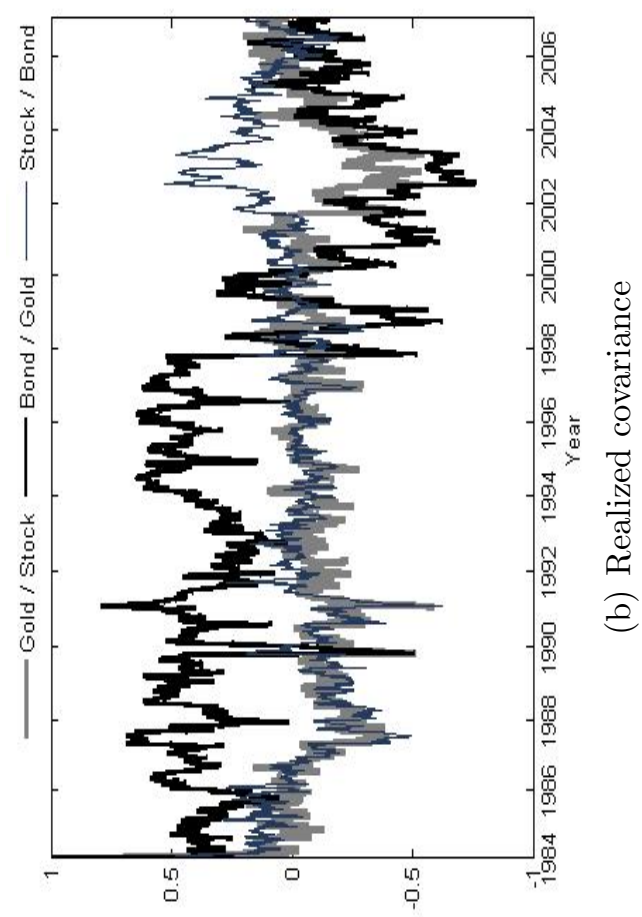

บํำ|อมกว

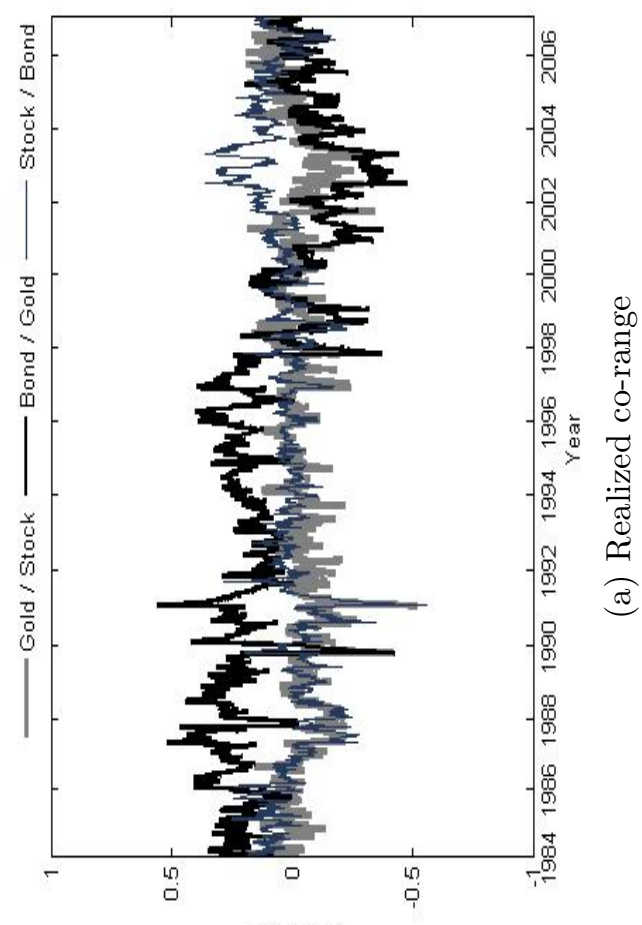

บоำ|วנมо

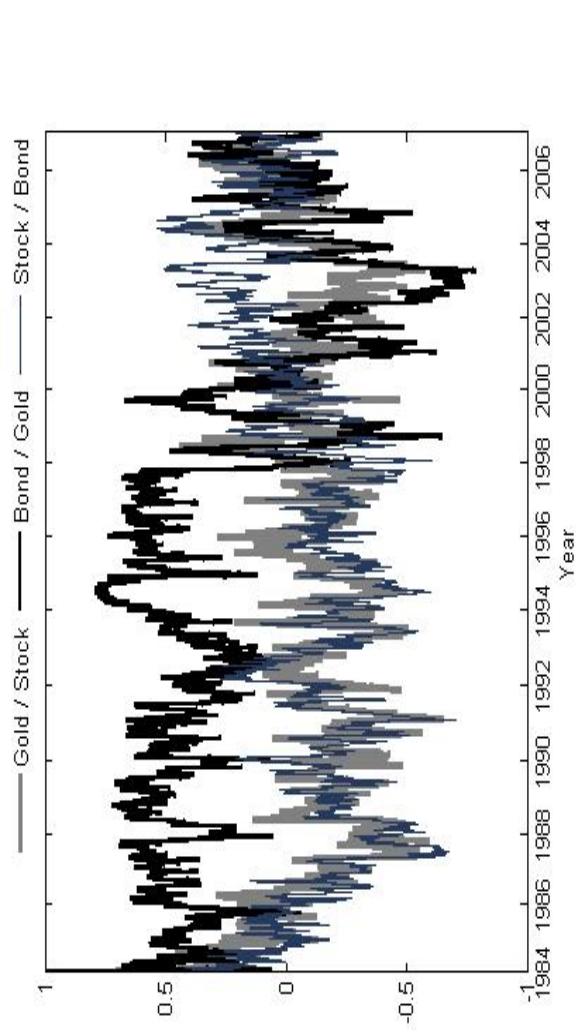

그음

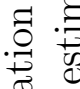

히 이

. $\Xi$

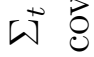

官 골

舜

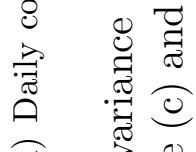

ซ

。

少

$\rightarrow$ 극

帛

응

ర్ల

节

ב

焉

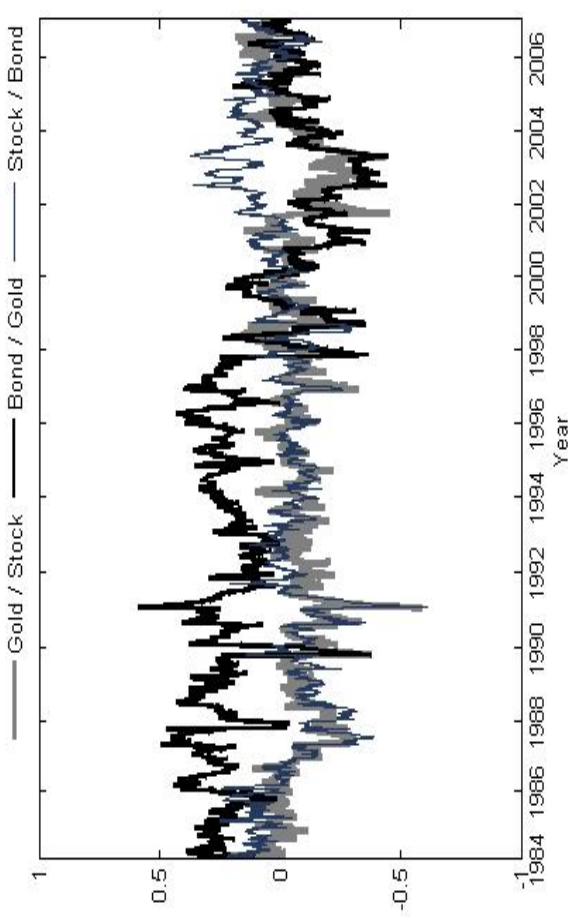

บำฺ|อมงว

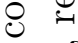

귤

곰

แ०

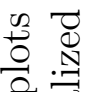

क

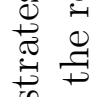

虽

0

(201

象

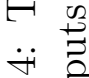

○. .

敌索 

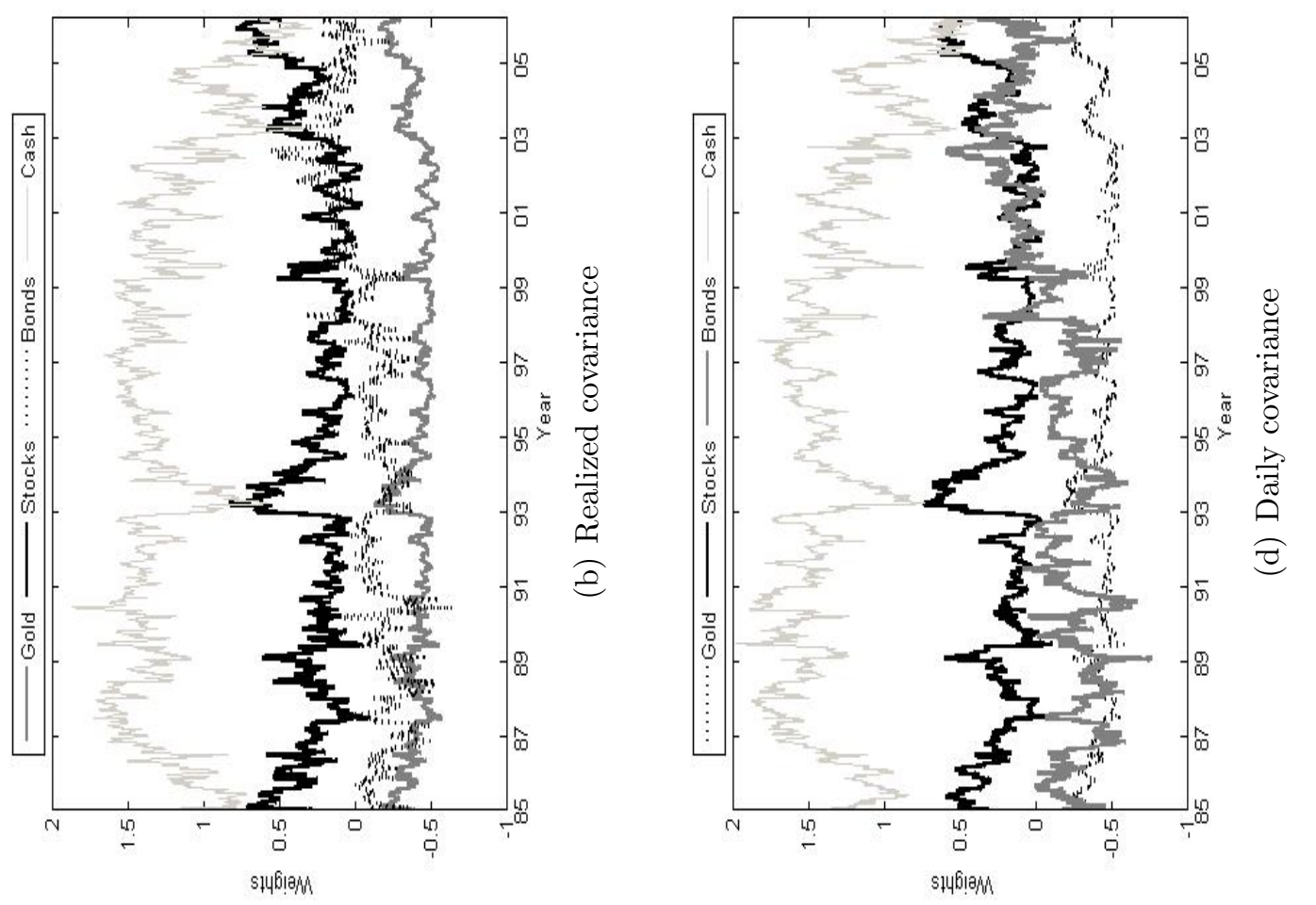

晃

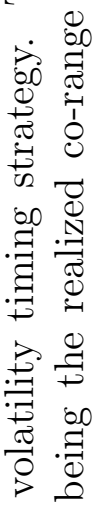

霅

疍

山ै

国.

.

응

ڤ్రి

导
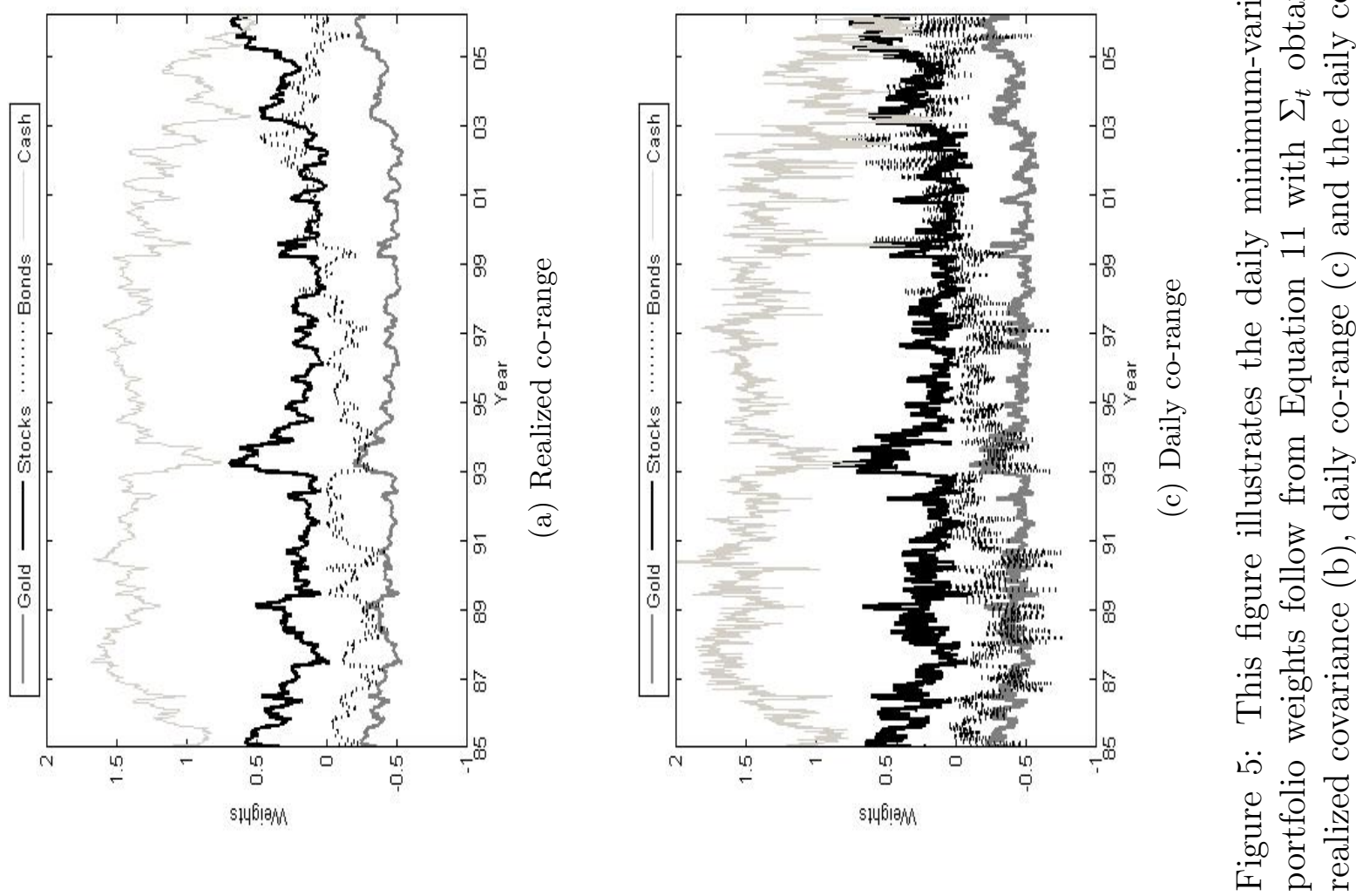